\title{
Therapeutic Approaches to the Regulation of Metabolism of High-Density Lipoprotein
}

\section{- Novel HDL-Directed Pharmacological Intervention and Exercise -}

\author{
Bo Zhang, PhD; Emi Kawachi, PhD; Shin-ichiro Miura, MD, PhD; \\ Yoshinari Uehara, MD, PhD; Akira Matsunaga, MD, PhD; \\ Masahide Kuroki, MD, PhD; Keijiro Saku, MD, PhD
}

\begin{abstract}
High-density lipoprotein (HDL) and low-density lipoprotein (LDL) particles transport cholesterol in plasma and play an important role in cellular cholesterol homeostasis, which influences cell function. The risk of coronary artery disease (CAD) associated with high levels of LDL-cholesterol (LDL-C) can be reduced by treatment with statins, which reduce LDL-C levels by inhibiting cellular cholesterol synthesis. However, patients who are treated with high doses of statins, especially secondary CAD prevention, regardless of their resulting LDL-C levels, are still at high risk of CAD. Therefore, there has been growing interest in HDL-directed therapies. Inhibitors of cholesteryl ester transfer protein (CETP) substantially increase HDL-C levels (by 31-138\%). However, it is still unclear whether or not CETP inhibitors can reduce the risk of CAD associated with low HDL-C levels, while reconstituted HDL or apolipoprotein A-I mimetic peptides increase the functionality of HDL. Low levels of HDL-C are often complicated with metabolic disorders, including hypertriglyceridemia, metabolic syndrome, and type 2 diabetes mellitus, and lifestyle changes are effective for correcting these conditions. Physical activity and exercise training increase HDL-C levels, especially HDL2-C levels, by multiple mechanisms. Therefore, although using HDL-directed therapies that increase $\mathrm{HDL}-\mathrm{C}$ levels and/or improve the function of $\mathrm{HDL}$ is a reasonable approach for reducing the residual risk of CAD as a complement to LDL-C-lowering therapy, lifestyle modifications including exercise to improve metabolic disorders should be considered as the first option. (Circ J 2013; 77: 2651-2663)
\end{abstract}

Key Words: Cholesteryl ester transfer protein; Coronary artery disease; Exercise training; High-density lipoprotein; Lifestyle change

$\mathbf{C}$ oronary artery disease (CAD) is a leading cause of death worldwide. Atherosclerosis results in angina and myocardial infarction (MI). Dyslipidemia is one of the many risk factors for CAD. High-density lipoprotein (HDL) and low-density lipoprotein (LDL) transport cholesterol in plasma and have direct effects on cellular cholesterol homeostasis, and an imbalance between HDL and LDL (ie, low HDL cholesterol [HDL-C] and high LDL-C levels) is associated with an increased risk of CAD.

A high plasma level of LDL-C is a major risk factor for CAD. Therapy with statins [inhibitors of 3-hydroxy-3-methylglutaryl coenzyme A (HMG-CoA) reductase], which inhibit cholesterol biosynthesis, effectively reduces the levels of both LDL-C and modified forms of LDL in human plasma, ${ }^{1-4}$ and significantly reduces the risk of $\mathrm{CAD},{ }^{5,6}$ as evidenced by primary and secondary clinical intervention studies. ${ }^{7,8}$
A low level of HDL-C is a risk factor for CAD, independent of LDL-C. ${ }^{7-9}$ Thus, the HDL-C level inversely correlates with the risk of CAD regardless of whether the LDL-C level is low or high. The causes of low HDL-C levels are multiple and complex. The HDL-C level is under strong genetic control, and multiple genes that influence the HDL-C level have been identified. ${ }^{10,11}$ However, single nucleotide polymorphisms (SNP) in the multiple genes that raise or lower HDL-C levels do not seem to predict the risk of $\mathrm{MI},{ }^{12,13}$ which suggests that low HDL-C levels per se do not cause CAD and that the influence of environmental factors (eg, lifestyle) on HDL-C levels should be emphasized. In fact, a low HDL-C level is often complicated with metabolic disorders, including hypertriglyceridemia (HTG), metabolic syndrome (MetS), and type 2 diabetes mellitus (T2DM). ${ }^{14}$ Also, physical activity has been shown to modify the effects of LPL gene polymorphism, which is asso-

Received December 25, 2012; revised manuscript received September 9, 2013; accepted September 18, 2013; released online October 10, 2013 Department of Biochemistry (B.Z., M.K.), The AIG Collaborative Research Institute of Cardiovascular Medicine (B.Z., S.M., Y.U., A.M., K.S.), Department of Cardiology (E.K., S.M., Y.U., K.S.), Department of Molecular Cardiovascular Therapeutics (S.M., Y.U., K.S.), and Department of Laboratory Medicine (A.M.), Fukuoka University School of Medicine, Fukuoka, Japan

Mailing address: Bo Zhang, MS, PhD, Department of Biochemistry, Fukuoka University School of Medicine, 7-45-1, Nanakuma, Jonan-ku, Fukuoka 814-0180, Japan. E-mail: bozhang@fukuoka-u.ac.jp or Keijiro Saku, MD, PhD, FACP, FACC, Department of Cardiology, Fukuoka University School of Medicine, 7-45-1, Nanakuma, Jonan-ku, Fukuoka 814-0180, Japan. E-mail: saku-k@ fukuoka-u.ac.jp

ISSN-1346-9843 doi:10.1253/circj.CJ-12-1584

All rights are reserved to the Japanese Circulation Society. For permissions, please e-mail: cj@j-circ.or.jp 


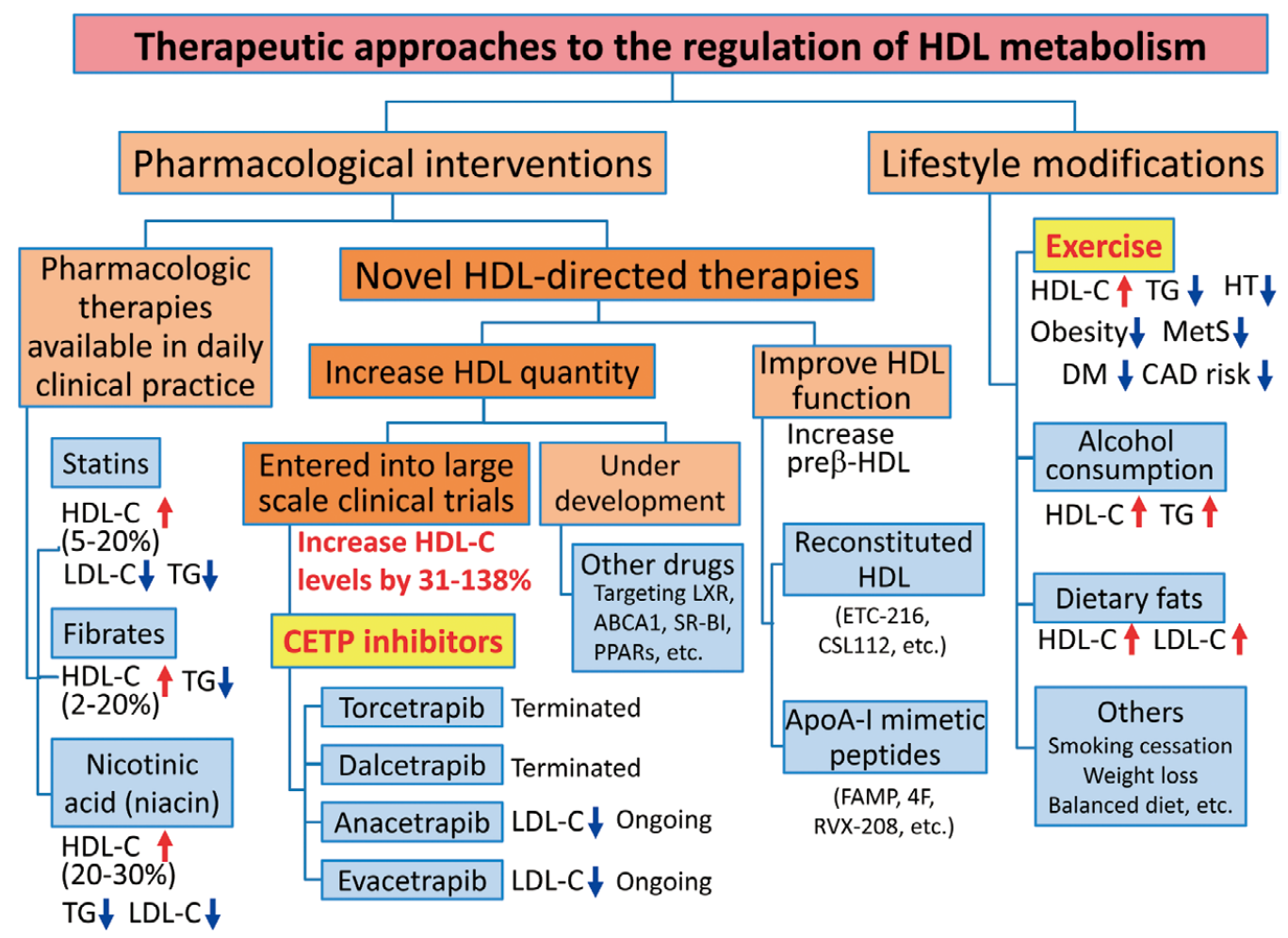

Figure 1. Therapeutic approaches to the regulation of high-density lipoprotein (HDL) metabolism include pharmacological interventions and lifestyle modifications. Statins, fibrates, and nicotinic acid (niacin) are available in daily clinical practice and moderately increase the HDL cholesterol (HDL-C) level. The novel HDL-directed therapies include those that increase HDL quantity and HDL function. Cholesteryl ester transfer protein (CETP) inhibitors, torcetapib, dalcetrapib, anacetrapib, and evacetrapib, have entered large-scale clinical trials and substantially increase the HDL-C level (31-138\%), but 2 of the trials have been terminated in failure or because of insufficient outcomes. Reconstituted HDL and apoA-I mimetic peptides are also novel HDL-directed therapies that improve the function of HDL. Among lifestyle modifications, exercise, the moderate consumption of alcohol, dietary fat intake, and smoking cessation all increase the HDL-C level. However, alcohol consumption also increases the triglycerides (TG) level and dietary fat intake increases the low-density lipoprotein cholesterol (LDL-C) level. Regular exercise decreases TG levels and reduces both the risk factors associated with coronary artery disease (CAD), including obesity, hypertension (HT), type2 diabetes mellitus (DM), and metabolic syndrome (MetS), and the risk of CAD.

ciated with HDL-C levels, on the risk of MI in women of European ancestry. ${ }^{15}$

In addition to their LDL-C-lowering effects, statins raise HDL-C levels by 5-20\%. ${ }^{16}$ However, patients who are treated with high doses of statins, regardless of their treated LDL-C level, are still at considerable risk for cardiovascular disease. ${ }^{17,18}$

Therefore, HDL-directed therapies ${ }^{19}$ have gained attention with regard to their potential to reduce the residual risk of CAD. Inhibitors of cholesteryl ester (CE) transfer protein (CETP) substantially increase HDL-C levels (by 31-138\%) (Figure 1), ${ }^{20,21}$ but it is not yet clear whether CETP inhibitors reduce the risk of $\mathrm{CAD}$.

Because CAD has multiple risk factors, an overall reduction of CAD risk factors in addition to elevated HDL-C levels is necessary for the prevention of CAD. ${ }^{22,23}$ Lifestyle changes are effective for primary and secondary cardiovascular disease prevention. Physical activity and exercise training increase HDL2$\mathrm{C}$ levels ${ }^{24}$ and have many atheroprotective effects (Figure 1). ${ }^{25}$

This review provides a brief summary of the role of HDL in plasma cholesterol transport, HDL heterogeneity and function. Therapeutic approaches to the regulation of HDL me- tabolism are categorized as pharmacological interventions and lifestyle modifications (Figure 1), and the relation between the HDL-C-raising effects of CETP inhibitors and CAD risk, new approaches to increasing HDL functionality, the HDL-Craising effects of lifestyle modifications, especially exercise training, and the mechanisms by which exercise raises HDL-C levels are discussed.

\section{Role of HDL in Cholesterol Homeostasis}

Role of HDL in Reverse Cholesterol Transport (RCT)

Cholesterol is transported in plasma by lipoproteins. Free cholesterol (FC) is contained in the outer phospholipid (PL) monolayer of lipoproteins, together with apolipoproteins and other proteins, and $\mathrm{CE}$ is contained in the core of lipoproteins together with triglycerides (TG).

The liver is the major site of cholesterol synthesis. Dietary cholesterol, which is absorbed by the small intestine, is transported to the liver by chylomicrons (CM). These 2 sources of cholesterol are packaged in the liver into very low-density lipoprotein (VLDL), which is secreted into plasma. Plasma VLDL is catabolized into intermediate-density lipoprotein 


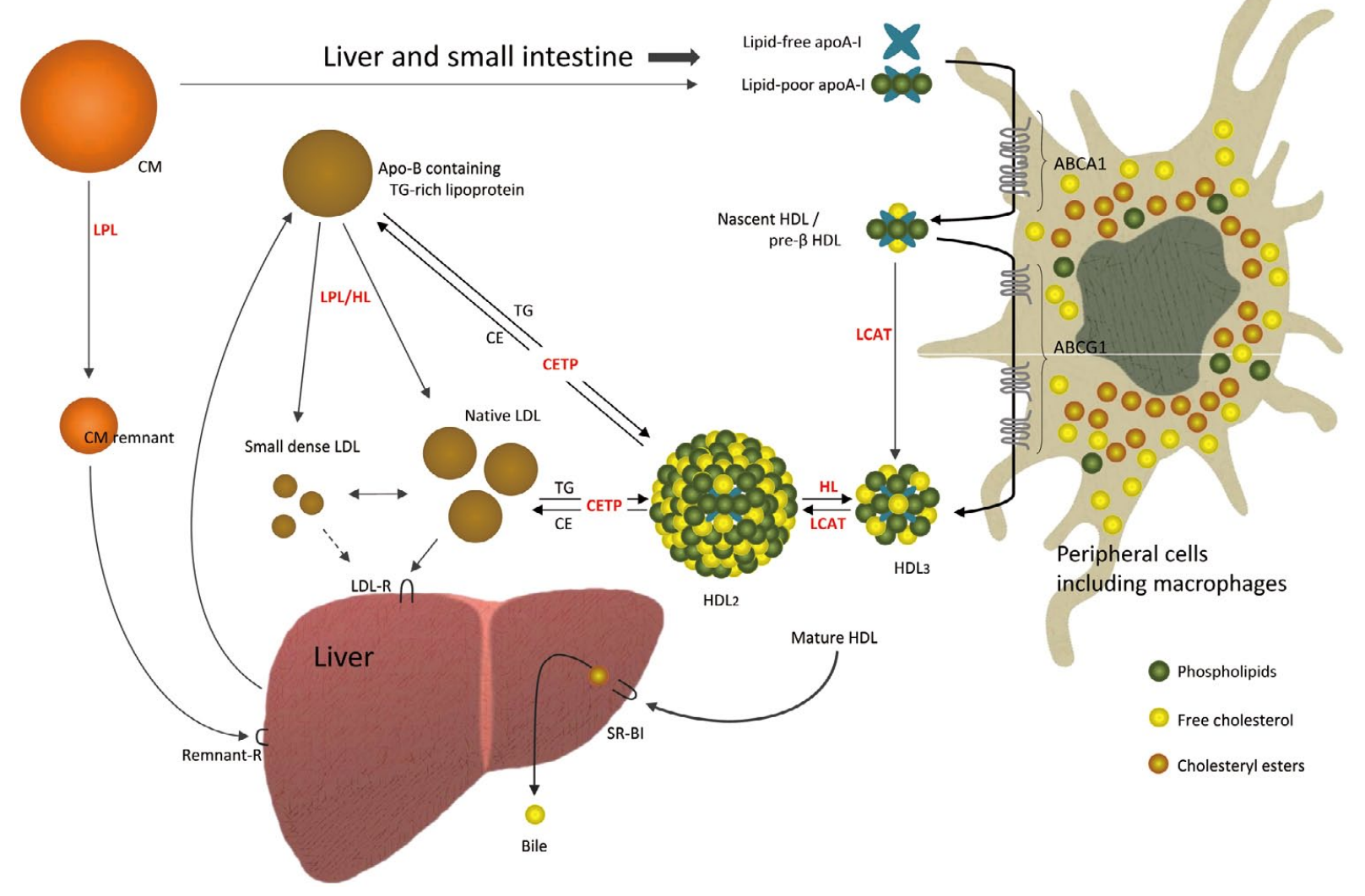

Figure 2. High-density lipoprotein (HDL) metabolism and reverse cholesterol transport. Apo A-I is synthesized by the liver and intestine, and secreted into plasma as lipid-poor apoA-I, which efficiently removes cholesterol from cells by interacting with ABCA1, followed by the esterification of cholesterol by the enzyme LCAT (lecithin:cholesterol acyltransferase). The more lipidated HDL then accepts cholesterol that is transported to the cell surface by ABCG1 or ABCG4. Cholesterol ester (CE) in mature HDL is transferred to plasma apo-B containing lipoproteins (eg, very low-density lipoprotein [VLDL]) by the action of cholesteryl ester transfer protein (CETP) in exchange for triglyceride (TG), or removed from plasma by the liver via the selective uptake of HDL-CE by scavenger receptor class B type I (SR-BI) or HDL holoparticle uptake by receptors for HDL holoparticles. HL, hepatic lipase; LPL, lipoprotein lipase.

(IDL) and then into LDL after the hydrolysis of TG by the action of lipoprotein lipase (LPL) and hepatic lipase (HL), respectively. LDL-containing cholesterol is used by peripheral cells through the endocytosis of LDL particles by LDL-R (Figure 2). ${ }^{26}$

HDL particles are major acceptors of FC that has been effluxed from cells. FC (ie, non-esterified cholesterol) is pumped from cells to HDL through 2 transmembrane proteins: adenosine triphosphate (ATP)-binding cassette (ABC) transporters A1 and G1 (ABCA1 and ABCG1). ${ }^{27}$ ABCG4, a transporter of unknown function, has very recently been shown to be highly expressed in bone marrow megakaryocyte progenitors and promote the efflux of cellular cholesterol to HDL in these cells. ${ }^{28}$ ABCA1 and ABCG1 are transcriptionally regulated by liver X receptor (LXR) upon heterodimerization with retinoid $X$ receptor (RXR). ${ }^{29}$ LXR functions as a nuclear cholesterol sensor that is activated in response to elevated intracellular cholesterol. ${ }^{30}$ Apolipoprotein (apo) A-I, the major protein of HDL, is synthesized by the liver and intestine, and secreted into plasma as lipid-poor apoA-I or discoidal nascent HDL. Lipid-poor apoAI efficiently removes cholesterol from cells by interacting with
ABCA1, followed by esterification of cholesterol by the enzyme lecithin:cholesterol acyltransferase (LCAT). ${ }^{27}$ The more lipidated HDL then accepts cholesterol that is transported to the cell surface by ABCG1 (Figure 2). ${ }^{27}$

Nascent HDL removes cellular cholesterol and matures into spherical HDL by the action of LCAT. CE in mature HDL is transferred to plasma apo-B containing lipoproteins (eg, VLDL and IDL) by the action of CETP in exchange for TG (Figure 3 ), or removed from plasma by the liver via the selective uptake of HDL-CE by scavenger receptor class B type I (SR-BI) or HDL holoparticle uptake by receptors for HDL holoparticles (Figure 2). ${ }^{11}$ Thus, HDL transports cholesterol from peripheral cells to the liver for excretion (known as reverse cholesterol transport, RCT). ${ }^{31}$

\section{HDL Heterogeneity, Remodeling, and Function}

HDL consists of heterogeneous particles that differ in shape, electric charge, and composition of lipids and proteins. ${ }^{32,33}$ HDL is separated into spherical alpha-migrating HDL and prebeta-migrating HDL (pre- $\beta$ HDL) on agarose gel according to electrophoretic mobility. ${ }^{34}$ Ultracentrifugation separates HDL 

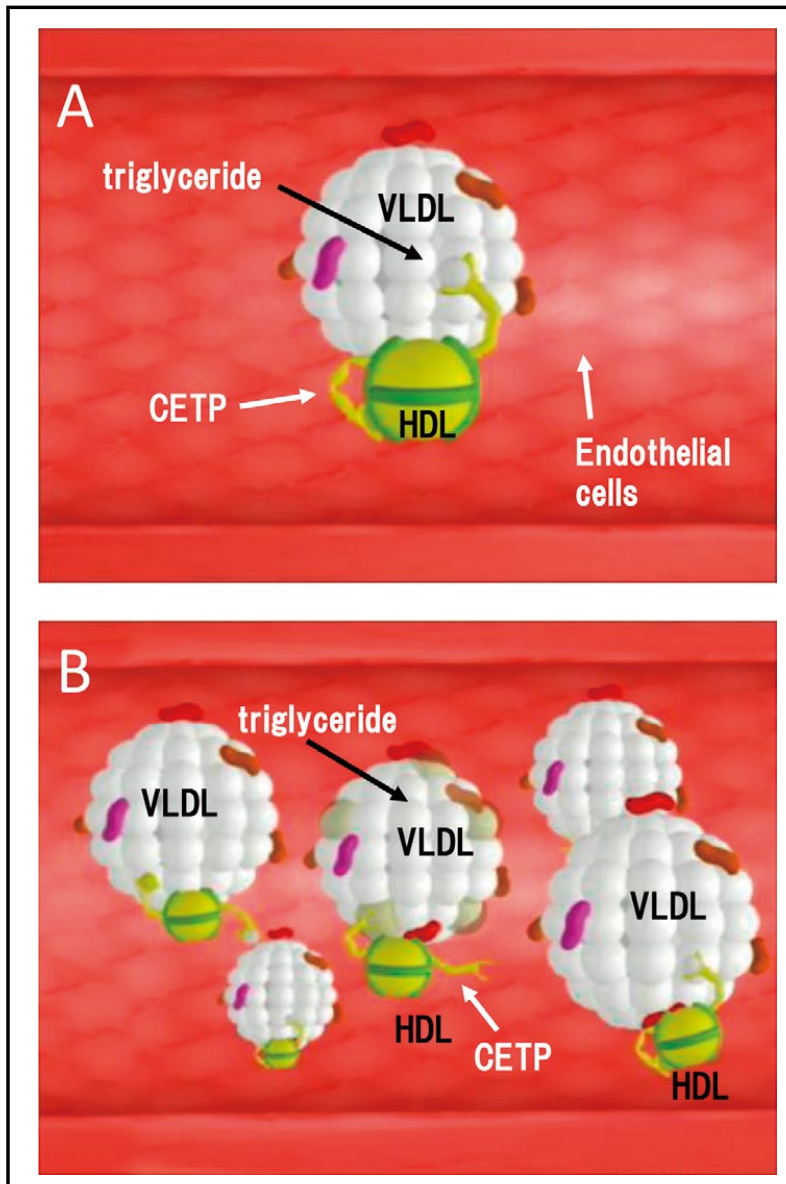

Figure 3. Classical cholesteryl ester transfer protein (CETP) pathway. Cholesterol ester in high-density lipoprotein (HDL) is transferred to very low-density lipoprotein (VLDL) in exchange for triglyceride (TG) via the action of CETP. When VLDL levels are low, this process is slow (A). However, when the production of VLDL increases, this process occurs rapidly, which increases the catabolic rate of HDL particles (B).

into large $\mathrm{HDL}_{2}(1.063-1.125 \mathrm{~g} / \mathrm{ml})$ and small $\mathrm{HDL}_{3}(1.125-$ $1.21 \mathrm{~g} / \mathrm{ml}$ ) subfractions on the basis of density. ${ }^{33}$ Pre $-\beta$ HDL, $\mathrm{HDL}_{3}$, and $\mathrm{HDL}_{2}$ are functionally distinct particles. Discoidal nascent HDL (lipid-poor apoA-I) and pre- $\beta$ HDL are the most efficient acceptors of FC effluxed from cells via $\mathrm{ABCA} 1^{11}$ or TG-rich lipoproteins (TRL). ${ }^{35,36}$ Small HDL3 particles are better acceptors of FC effluxed from cells via ABCG1 than large $\mathrm{HDL}_{2}$ particles. ${ }^{11}$

HDL particles are continuously remodeled by plasma factors. ${ }^{32}$ LCAT converts discoidal HDL into spherical HDL and increases the size of HDL by converting $\mathrm{HDL}_{3}$ into HDL2. $\mathrm{HDL}_{2}$ is converted back into $\mathrm{HDL}_{3}$ with the shedding of lipidpoor apoA-I from HDL by the action of CETP and HL (Figure 2). Lipid-poor apoA-I can be glomerularly filtered and catabolized by the kidney. ${ }^{37,38}$ Phospholipid transfer protein (PLTP) transfers PLs between HDL and TRL, as well as between different HDL particles. PLTP remodels HDL into large and small particles and lipid-poor apoA-I. ${ }^{34,39}$ Endothelial lipase (EL), which has phospholipase activity and hydrolyzes HDL PL, ${ }^{40}$ converts large HDL into small HDL. ${ }^{41,42}$ Cellular factors also remodel HDL. ABCA1 and ABCG1 are crucial for the formation of HDL, and the hepatic HDL receptor, SR$\mathrm{BI}$, which selectively uptakes HDL-CE, converts large HDL into small HDL. ${ }^{43,44}$ CETP (exogenous and cell-associated) also mediates the selective acquisition of CE from HDL by the liver, resulting in CE depletion of HDL.45,46

The protective effects of HDL against atherosclerosis are mainly related to its role in RCT, which unloads cholesterol from lipid-laden macrophages in atheroma. ${ }^{27}$ Transcytosis of lipid-poor apoA-I and HDL from plasma through aortic endothelial cells has been shown to be modulated by cell-surface ABCA1, ABCG1, SR-BI, and $\mathrm{F}_{0} \mathrm{~F}_{1}$ ATPase. ${ }^{47-49} \mathrm{HDL}$ also has many other atheroprotective properties: antioxidant, antiinflammatory, endothelium-protective, fibrinolytic, antithrombotic, antiapoptotic, immunosuppressive, and antidiabetic. ${ }^{16,50-55}$

However, HDL can be altered to become functionally deficient (impaired function) or dysfunctional (complete loss of function) in patients with, or who are high risk of, CAD and under conditions of infection and inflammation (Figure 4). ${ }^{11}$ The cholesterol efflux ability of apoB-depleted serum has been shown to be inversely associated with carotid atherosclerosis and the risk of CAD independent of the HDL-C level. ${ }^{56}$ The ability of HDL (apoB-depleted serum) to prevent the oxidation of LDL, as measured by an HDL inflammatory index, was reduced in patients with acute coronary syndrome (ACS).$^{57} \mathrm{HDL}$ from patients on chronic hemodialysis had reduced antichemotactic ability and an increased macrophage cytokine response. ${ }^{58}$ HDL separated from patients with CAD and high HDL-C promoted, but did not inhibit, monocyte chemotaxis. ${ }^{59} \mathrm{HDL}$ during an acute-phase response in patients after cardiac surgery became pro-inflammatory, and increased LDL oxidation and the secretion of monocyte chemotactic protein 1 (MCP-1) by cells in the artery wall. ${ }^{60}$

Therefore, the plasma HDL-C level may not reflect the function of HDL, depending on the metabolic background. Changes in the composition of HDL (surface proteins, core neutral lipids, and surface amphiphilic lipids) in metabolic conditions associated with accelerated atherosclerosis and elevated cardiovascular risk can impair its biologic activities (Figure 4). ${ }^{11}$ Recent proteomic analyses have identified more than 40 proteins in human HDL, ${ }^{61,62}$ which can be divided into several major subgroups: apolipoproteins (eg, apoA-I and apoA-II), enzymes [eg, LCAT and paraoxonase (PON1)], lipid transfer proteins (eg, CETP and PLTP), and minor proteins. ${ }^{11}$ These latter HDL proteins include acute-response proteins [eg, serum amyloid A (SAA)], complement components (eg, C3), and proteinase inhibitors (eg, alpha-2-antiplasmin).$^{11}$ Lipidomic analyses have identified more than 100 individual molecular species of lipids. ${ }^{63,64}$ HDL lipids include PLs (eg, phosphatidylcholine and sphingomyelin), steroids (eg, cholesterol and oxysterols), CE, TG, and minor lipids [eg, diacylglycerides, monoacylglyceride, free fatty acids, and lysosphingolipids]. ${ }^{11}$ Posttranslational oxidative modification of apoA-I, particularly through a myeloperoxidase (MPO) pathway, ${ }^{65,66}$ can also lead to HDL dysfunction (Figure 4), ${ }^{67,68}$ which dramatically reduces the ability of apoA-I to promote cholesterol efflux through the ABCA1 pathway. ${ }^{69}$

\section{Pharmacological Interventions That Regulate HDL Metabolism}

Because a low level of HDL-C is a major risk factor in patients who are treated aggressively for LDL-C, ${ }^{9}$ raising the HDL-C level is considered to be a promising approach to reducing the residual risk of cardiovascular disease as a complement to LDL-C-lowering therapy. ${ }^{70}$ However, because of the complexity of HDL metabolism, it is not easy to raise the HDL-C level. 


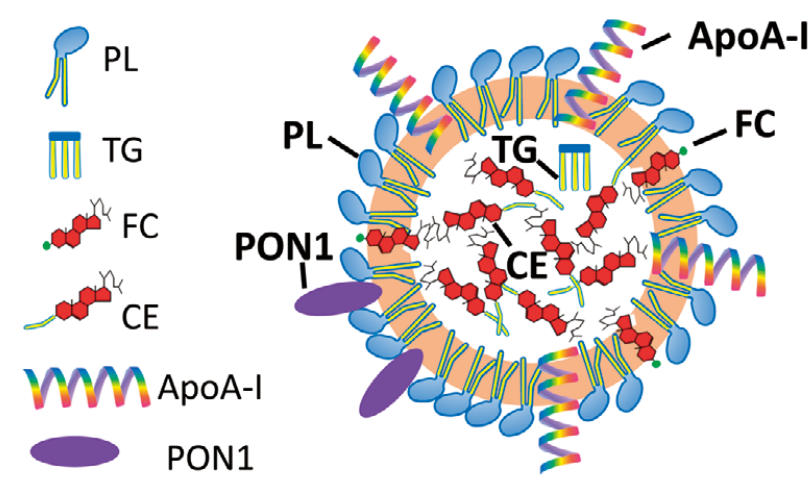

Normal HDL
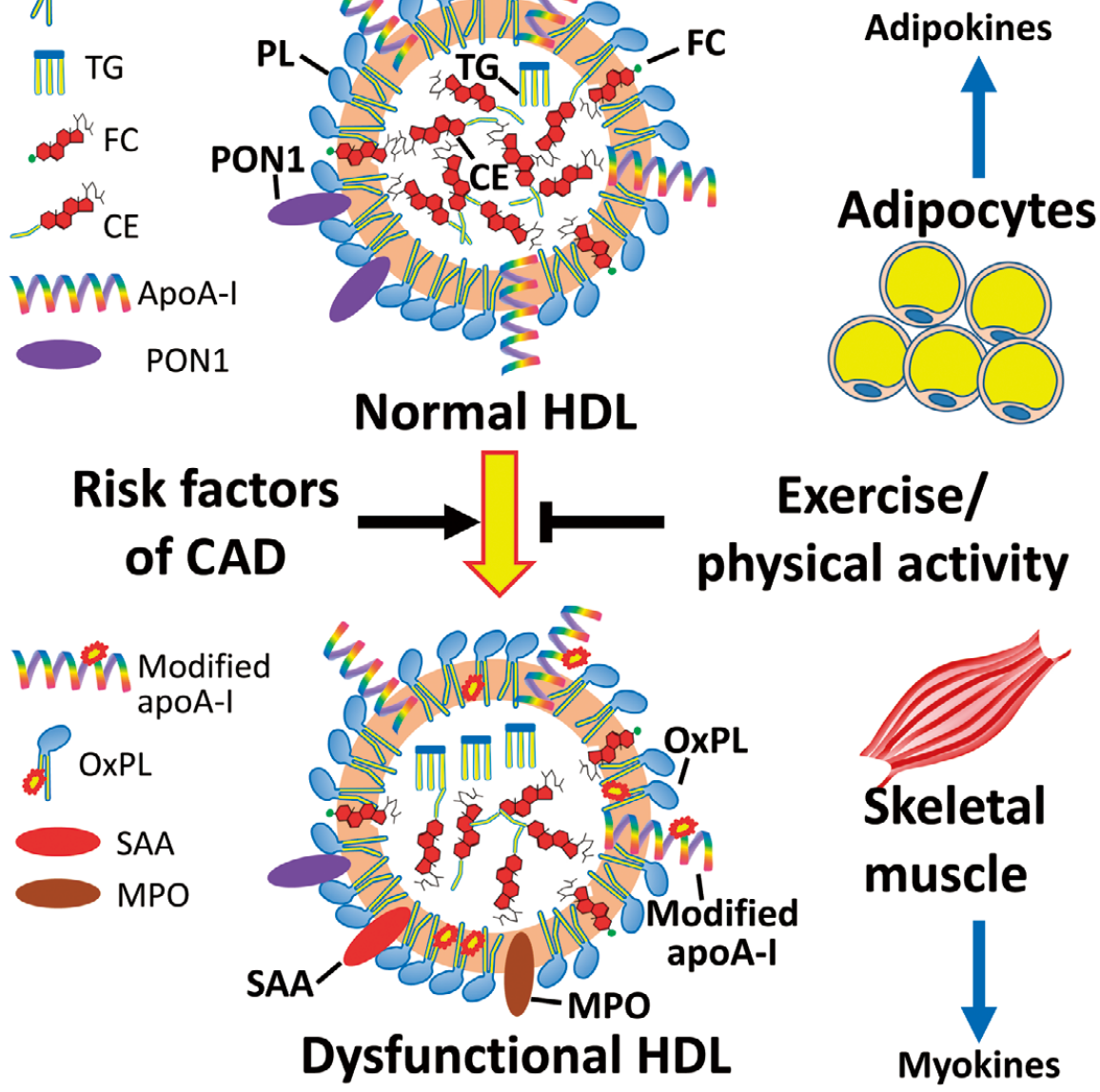

Exercise/

physical activity

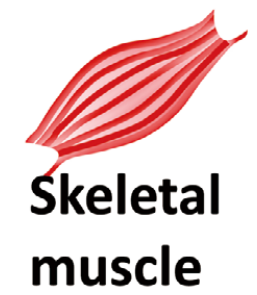

Figure 4. Schematic illustration of models of normal high-density lipoprotein (HDL) and functionally defective HDL. Plasma HDL particles consist of lipids and proteins. Free cholesterol (FC), apoA-I, paraoxonase (PON1), and other proteins are contained in the outer phospholipid monolayer of HDL. Esterified cholesterol (CE) and a small amount of triglyceride (TG) are contained in the core of HDL. The changes in the composition of HDL [increased TG content, reduced PON1, association of myeloperoxidase (MPO), replacement of apoA-I with the acute phase protein serum amyloid A (SAA)], and oxidative modifications of phospholipids $(\mathrm{OxPL})$ can occur under the metabolic conditions associated with accelerated atherosclerosis and an increased risk of coronary artery disease (CAD), and cause impaired biological activity of HDL (functionally defective HDL or dysfunctional HDL). Exercise and physical activity reduce the risk factors for CAD and improve the function of HDL. The protective effects involve favorable changes in adipokines and myokines secreted by adipocytes and skeletal muscle, respectively.

Pharmacologic Therapies That Raise the HDL-C Level

Currently available lipid-modulating drugs have modest effects on the HDL-C level (Figure 1).

Statins Statins raise the HDL-C level by $5-20 \% .{ }^{16}$ Among the various statins, pitavastatin has the strongest HDL-C-raising effect (see review by Yamashita et $\mathrm{al}^{16}$ ). Statins increase the HDL-C level by increasing the production of HDL in the liver because of increased hepatic expressions of apoA-I and ABCA $1 .{ }^{16}$

Fibrates Fibrates, agonists of peroxisome proliferatoractivated receptor $\alpha$ (PPAR $\alpha),{ }^{71}$ raise the level of HDL-C by $2-20 \%$ depending on the TG level. ${ }^{72}$ Fibrates increase the HDL-C level by increasing the hepatic synthesis of the major HDL apoproteins ${ }^{73}$ apoA-I and apoA-II, by activating PPAR $\alpha .{ }^{74}$

Nicotinic Acid (Niacin) Nicotinic acid (niacin) raises the HDL-C level by $20-30 \%,{ }^{75}$ which makes it the most effective HDL-C-raising drug currently available, but its use is limited because of its adverse effect of skin flushing. ${ }^{76}$ In addition, a recent meta-regression analysis did not support the claim that niacin-raised HDL-C levels are beneficial. ${ }^{.7}$ Niacin increases the HDL-C level by decreasing the catabolism of HDL-apoAI without altering the production of apoA-I in the liver. ${ }^{78}$

\section{Novel HDL-Directed Drugs That Raise HDL-C Levels: Do CETP Inhibitors Reduce the Risk of CAD?}

A deficiency of CETP, which results in markedly reduced rates of turnover of apoA-I, ${ }^{79}$ is a monogenic cause of inherited high HDL (4-6-fold greater than normal) in humans. ${ }^{36,80}$ Therefore, CETP inhibition is the target of a pharmacological approach to raising HDL-C to decrease the risk of cardiovascular disease. Small-molecule CETP inhibitors that have entered clinical development, including torcetrapib, ${ }^{81-84}$ dalcetrapib, ${ }^{21,85,86}$ anacetrapib, ${ }^{20,87}$ and evacetrapib, ${ }^{88,89}$ significantly increase the HDL-C level in humans. They also decrease LDL-C levels, except dalcetrapib, which has minimal effect on the LDL-C level. ${ }^{86}$

Torcetrapib Torcetrapib has not shown any protective 


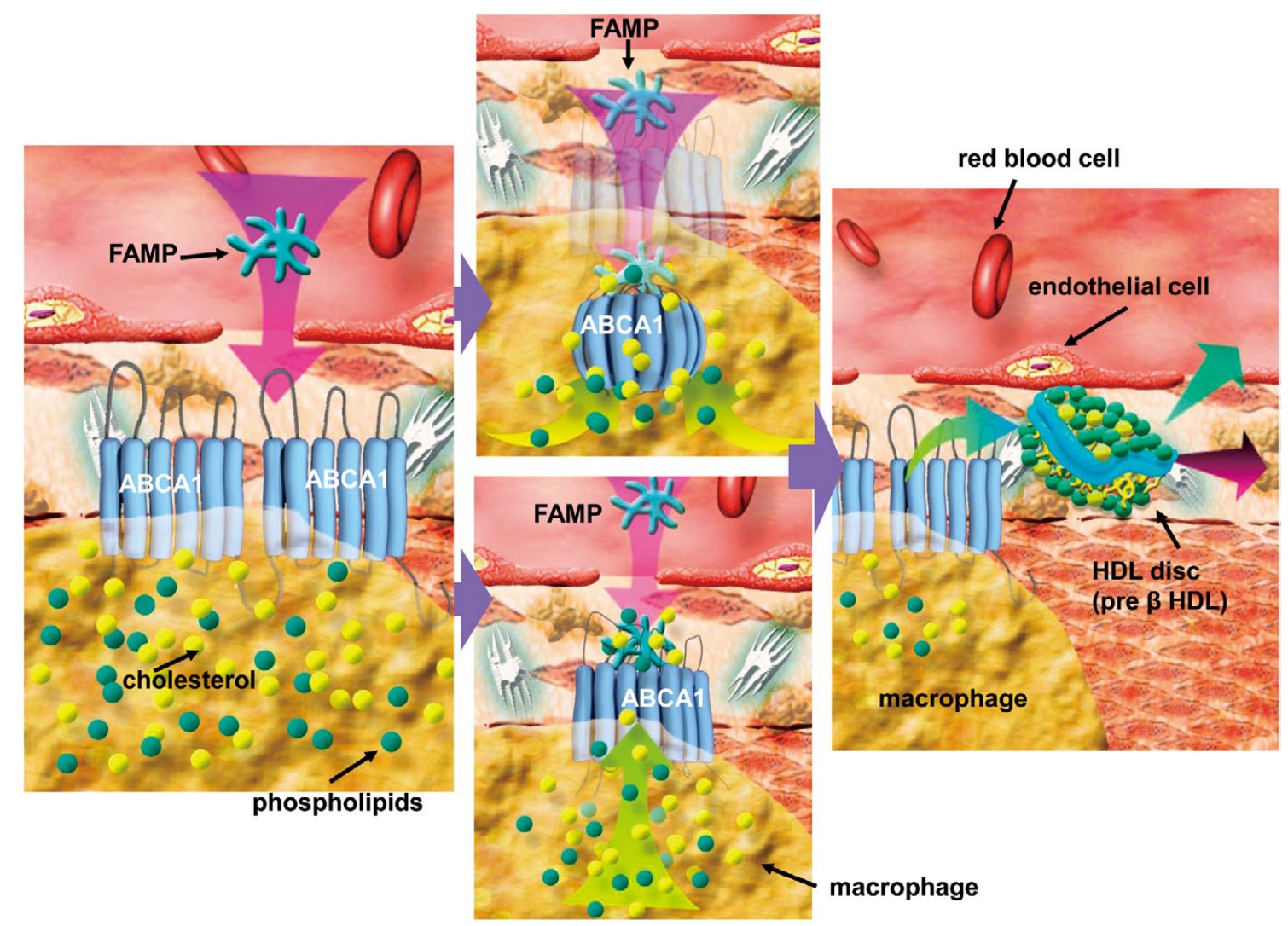

Figure 5. FAMP, a novel apoA-I mimetic peptide that is small with 24 amino acids, has been shown to enhance the function of high-density lipoprotein (HDL). ${ }^{101}$ FAMP may induce cellular cholesterol efflux by 2 mechanisms: (1) internalization and transcytosis in macrophages or aortic endothelial cells, and the removal of intracellular cholesterol (Upper middle panel), and (2) physical interactions between FAMP and ABCA1 to transport intracellular cholesterol to the circulation (Lower middle panel), and this latter mechanism may be predominant.

effects against coronary atherosclerosis in atorvastatin-treated patients with CAD, as demonstrated in the ILLUSTRATE trial, ${ }^{81}$ or against carotid atherosclerosis in atorvastatin-treated patients with familial hypercholesterolemia $(\mathrm{FH})$ and mixed dyslipidemia, as demonstrated in the RADIANCE 1 and 2 studies. ${ }^{82,83}$ Unexpectedly, torcetrapib therapy resulted in an increased risk of mortality and morbidity in patients who were at high risk of coronary events, which led to early termination of the ILLUMINATE trial. ${ }^{84}$ The adverse effects of torcetrapib were attributed to off-target effects of the drug, including an increase in blood pressure that resulted from the increased production of aldosterone $\mathrm{e}^{84,90}$ and impairment of endothelial function..$^{91,92}$

Dalcetrapib Dalcetrapib is a CETP modulator that inhibits the heterotypic transfer of neutral lipids (CE and TG) between HDL and apoB-containing lipoproteins (eg, VLDL and LDL; Figure 3), but preserves the homotypic transfer of CE among HDL particles (eg, from HDL 3 to HDL2). ${ }^{93,94}$ The safety of dalcetrapib was examined in patients with, or who were at high risk of, CAD in the dal-VESSEL and dal-PLAQUE trials. ${ }^{85,86}$ Dalcetrapib showed no adverse effects on endothelial function as assessed by brachial flow-mediated dilation, ${ }^{86}$ blood pressure, ${ }^{85,86}$ vessel structure as assessed by carotid MRI, ${ }^{85}$ and plaque size and arterial inflammation as assessed by PET/CT using ${ }^{18} \mathrm{~F}$-fluorodeoxyglucose as a tracer. ${ }^{85}$ The
dal-OUTCOMES trial tested the hypothesis that dalcetrapib reduces cardiovascular morbidity and mortality in patients with recent ACS. ${ }^{95}$ However, dalcetrapib did not reduce the risk of recurrent cardiovascular events, ${ }^{21}$ which resulted in termination of the dal-OUTCOMES trial because of futility, as well as all the studies in the dal-HEART program, which originally involved 6 clinical trials: dal-OUTCOMES (terminated), dalOUTCOMES 2, dal-PLAQUE, dal-ACUTE, dal-PLAQUE (completed), and dal-VESSEL (completed).

Anacetrapib The safety of anacetrapib was also examined in patients with, or who were at high risk of, CAD in the DEFINE trial. ${ }^{20}$ Anacetrapib did not result in the adverse cardiovascular effects observed with torcetrapib. ${ }^{20}$ Although dalcetrapib moderately increased the HDL-C (31-40\%) and had minimal effects on the LDL-C levles, ${ }^{21}$ anacetrapib increased HDL-C by $138 \%$ and also decreased LDL-C by $40 \%$ compared with placebo. ${ }^{20}$ The REVEAL trial, which aimed to determine whether anacetrapib reduces the risk of major coronary events in patients with circulatory problems (history of MI, cerebrovascular atherosclerotic disease, peripheral arterial disease, or T2DM with other evidence of symptomatic CAD) and who are treated with atorvastatin to lower their LDL-C levels, is ongoing and will be completed in 2017. ${ }^{96}$

Evacetrapib Evacetrapib is another novel CETP inhibitor that is being tested in a clinical outcome trial (ACCELERATE ${ }^{76}$ ). 
Similar to anacetrapib, it has effects on both the HDL-C and LDL-C level; it increased the HDL-C level by 54-129\% and reduced the LDL-C level by $36 \%$ in patients with dyslipidemia (high LDL-C or low HDL-C level), ${ }^{89}$ and does not increase blood pressure or induce aldosterone. ${ }^{88}$ The ACCELERATE trial aimed to test the effects of evacetrapib on cardiovascular outcomes (time to first occurrence of the composite endpoint of cardiovascular death, MI, stroke, coronary revascularization, or hospitalization for unstable angina) in patients who were at high risk for vascular disease..$^{97}$

It is still uncertain whether raising the HDL level by pharmacological therapy with CETP inhibitors can reduce the risk of $\mathrm{CAD}$, suggesting that raising the HDL-C level alone may not be enough to prevent CAD.

\section{Novel HDL-Directed Therapies That Improve the Function of HDL}

ETC-216 Nissen et al reported that 5-weekly intravenous infusions of a recombinant apoA-IMilano/PL complex (ETC216) caused significant regression of coronary atherosclerosis as measured by intravascular ultrasound (IVUS) in patients with ACS. ${ }^{98}$ A single infusion of reconstituted HDL in patients with heterozygous FH promoted RCT as indicated by an increase in fecal sterol secretion..$^{99}$

CSL112 A new formulation of full-length, plasma-derived human apoA-I (apoA-I/phosphatidylcholine complex) caused a strong and immediate increase in the ABCA1-dependent efflux capacity of plasma after infusion into rabbits. ${ }^{100}$

FAMP Recently, a peptide that mimics human apoA-I without complexing with PL, FAMP (Fukuoka University ApoA-I Mimetic Peptide), has been shown to enhance the function of HDL, and suppress aortic plaque formation in apoE-knockout mice fed a high-fat diet. ${ }^{101}$ FAMP markedly increases pre- $\beta$ HDL, and also increases overall cholesterol efflux from peripheral tissues. FAMP may enhance cellular cholesterol efflux by 2 mechanisms (Figure 5): (1) internalization and transcytosis in macrophages or aortic endothelial cells, and the removal of intracellular cholesterol, and (2) physical interactions between FAMP and ABCA1 to transport intracellular cholesterol to the circulation, and this latter mechanism may be predominant. Another apoA-I mimetic peptide, $4 \mathrm{~F}$, removes plasma oxidized lipids (PLs and fatty acids) and improves the antiinflammatory properties of HDL. ${ }^{102}$

\section{Lifestyle Modifications That Raise the HDL-C Level}

Low HDL-C levels are commonly associated with metabolic disorders and risk factors for CAD including HTG, insulin resistance, MetS, T2DM, and physical inactivity. Lifestyle changes are effective for primary and secondary cardiovascular disease prevention and are recommended in guidelines for clinical practice..$^{22,23}$ Lifestyle modifications, including exercise, smoking cessation, weight loss, moderate alcohol consumption and dietary fat intake, may increase the HDL-C level (Figure 1), typically by 5-10\%. ${ }^{11,103}$ However, alcohol consumption increases the TG level, ${ }^{104}$ and dietary fats also increase the LDL-C level. ${ }^{105,106}$ Physical activity and regular exercise decrease the TG level and reduce many of the risk factors of CAD, including obesity, hypertension (HT), and T2DM, as well as the risk of CAD (Figure 1). ${ }^{25}$ Regular physical activity and aerobic exercise training are related to a reduced risk of fatal and non-fatal coronary events in healthy individuals, subjects with coronary risk factors, and cardiac patients over a wide age range, ${ }^{22}$ and therefore this review focuses on the effects of exercise on HDL metabolism.

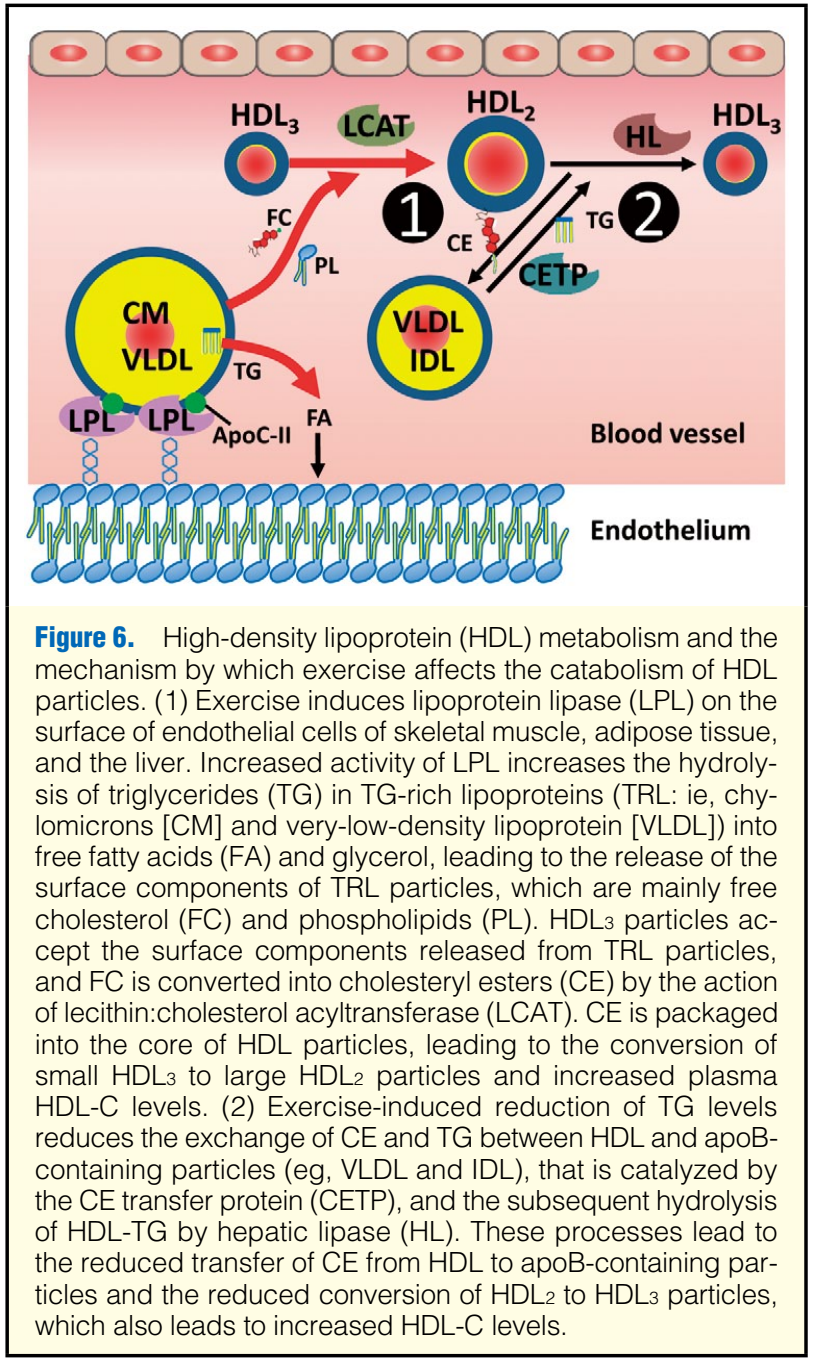

HDL-C-Raising and Atheroprotective Effects of Exercise

Exercise training has consistently been shown to increase HDL-C levels, especially HDL2-C levels, in normal, overweight, and hypercholesterolemic subjects, patients with T2DM, and patients with CAD. ${ }^{107-118}$

Exercise training increases the HDL-C level by $2.53 \mathrm{mg} / \mathrm{dl},{ }^{110}$ which should be associated with a decrease in cardiovascular risk of approximately $7 \%$, according to epidemiological data on the relationship between HDL-C and the risk of CAD. ${ }^{11}$ However, physical activity is associated with a much greater reduction in the risk for developing CAD (30-35\%). ${ }^{25}$ In fact, short-term exercise training has been shown to increase HDL function (antioxidant capacity) without significant changes in the HDL-C levels in patients with MetS. ${ }^{119} \mathrm{In}$ addition to its HDL-C-raising effect, exercise training has also been shown to have many other atheroprotective effects, including the preservation of endothelial function, and antioxidative and antiinflammatory effects. ${ }^{120-122}$ The mechanism of the antiinflammatory effects of exercise involves reduction of visceral fat mass, increased production and release of inflammatory cytokines from contracting muscle (Figure 4), and reduced expression of Toll-like receptors on monocytes and macrophages. ${ }^{122}$ Skeletal muscle has recently been identified as an endocrine organ that produces, expresses, and releases cytokines and other peptides, which are called myokines. ${ }^{123-125}$ Myokines appear to be in- 


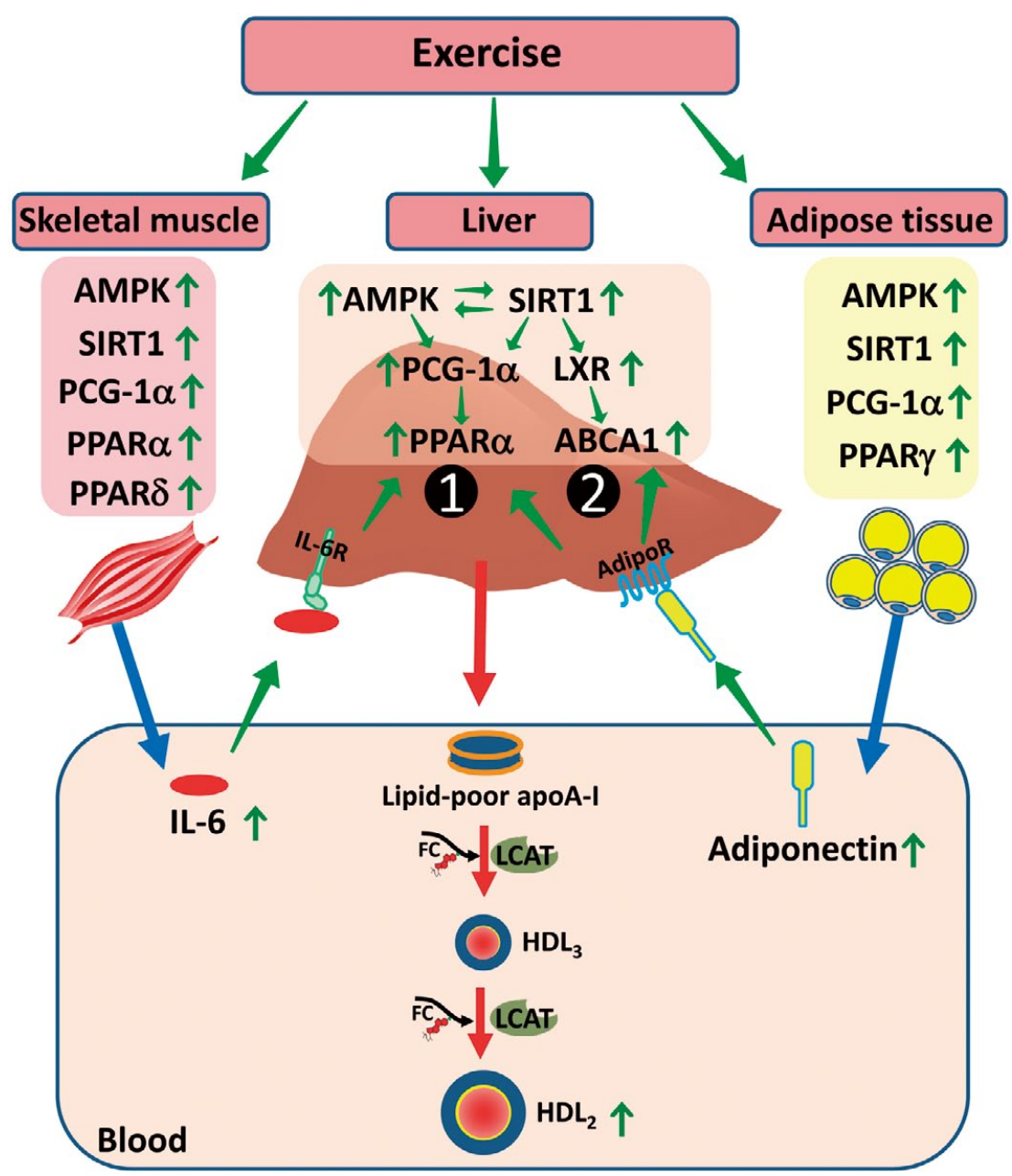

Figure 7. Mechanism by which exercise increases the production of high-density lipoprotein (HDL) particles. Exercise increases AMP-activated protein kinase (AMPK), SIRT1 (a mammalian sirtuin), and peroxisome proliferator-activated receptor (PPAR) $Y$ coactivator 1a (PCG-1a) in skeletal muscle, adipose tissue, and the liver. AMPK activates SIRT1, and SIRT1 in turn activates AMPK. Both AMPK and SIRT1 activate PCG-1a, leading to the coactivation of nuclear receptors including PPARs. Activation of PPARa in the liver leading to the increased synthesis of apolipoprotein (apo) A-I. SIRT1 also activates liver X receptor (LXR) independent of PCG-1a, leading to the increased expression of ABCA1 transporter, a target gene of LXR that is responsible for cholesterol efflux from cells to apoA-l/lipid-poor apoA-I. Therefore, both the activation of PPARa and increased expression of ABCA1 (indicated by the numbers 1 and 2) result in the increased production of lipid-poor apoA-I, which, by acquiring free cholesterol (FC) and phospholipids $(\mathrm{PL})$ from peripheral cells or from hydrolysis of triglyceride-rich lipoproteins, is rapidly converted to mature HDL particles by the action of LCAT. Skeletal muscles release a large quantity of interleukin-6 (IL-6), a myokine (cytokines secreted from muscle), into the blood during contraction. Exercise also increases the plasma concentration of adiponectin, an adipokine (cytokines secreted from adipocytes). IL-6 and adiponectin activate PPARa by binding to their respective receptors, IL-6 receptor (IL-6R) and adiponectin receptor (AdipoR). Therefore, the systemic effects of IL-6 and adiponectin on the liver may also contribute to exerciseinduced HDL neogenesis.

volved in the mediation of exercise-induced antiinflammatory, immunoregulatory, and metabolic effects. ${ }^{123-126}$

\section{Mechanisms of the HDL-Raising Effects of Exercise}

The mechanisms by which exercise increases HDL-C levels involve exercise-induced changes in multiple tissues (adipose tissue, skeletal muscle, the liver, etc.) (Figures 6,7).

Exercise-induced adaptations in human skeletal muscle tissue (higher LPL activity and VLDL-TG uptake) are largely responsible for the increased HDL-C and HDL2-C levels. ${ }^{24}$ Increased hydrolysis of TRL by increased LPL activity ${ }^{118,127}$ leads to the release of FC, PL, and apoC-II on the surface of
TRL. HDL3 particles accept these surface components of TRL. ${ }^{35} \mathrm{FC}$ is subsequently esterified into CE by LCAT and packaged into the core of HDL particles. ${ }^{35}$ By this process, $\mathrm{HDL}_{3}$ is converted into larger HDL2 particles, ${ }^{35}$ leading to an increased $\mathrm{HDL}_{2}-\mathrm{C}$ level (Figure 6). In fact, the effects of endurance exercise training on HDL-C and $\mathrm{HDL}_{2}-\mathrm{C}$ levels has been shown to depend on the TG levels in healthy sedentary men. ${ }^{128}$ Also, exercise caused changes in the distribution of HDL subfractions (increased $\mathrm{HDL}_{2}-\mathrm{C}$ and decreased HDL3-C) in hypercholesterolemic men, ${ }^{114}$ and increased the size of HDL particles in overweight men and women with dyslipidemia. ${ }^{115}$ However, evidence regarding the predictive value of the HDL2- 
$\mathrm{C}$ and $\mathrm{HDL}_{3}-\mathrm{C}$ levels against $\mathrm{CAD}$ is conflicting in humans, and controversy also exists in regard to the relative importance of the HDL subfractions. ${ }^{129,130}$

An inverse relationship is known to exist between the TG and HDL-C levels. The action of CETP produces TG-rich HDL2 particles. HDL-TG is a substrate of HL and the hydrolysis of HDL2-TG and -PL by HL causes the conversion of HDL2 to HDL3 particles. ${ }^{35}$ Therefore, the exercise-induced reduction in the plasma TG level ${ }^{113,115,116,118,128}$ and decreased HL activity ${ }^{118}$ also partly contribute to the increased HDL-C and $\mathrm{HDL}_{2}-\mathrm{C}$ levels (Figure 6).

Exercise training reduces the amount of abdominal visceral and subcutaneous fat in obese women with MetS, ${ }^{131}$ and these changes in body fat negatively correlate with those in HDL-C and HDL $2-\mathrm{C}^{132}$ Although the mechanism by which exerciseinduced changes in adipose tissue increases the HDL-C level is not fully understood, adiponectin, an antiinflammatory cytokine ${ }^{133}$ synthesized by adipocytes and present in high levels in the blood, ${ }^{134}$ mediates the effects of exercise on HDL-C. Plasma adiponectin concentrations have been shown to correlate positively with HDL-C levels in men and women. ${ }^{135}$ In overweight/obese subjects with T2DM, lifestyle intervention (increased physical activity and reduced caloric intake) increased the adiponectin concentration by $11.9 \%$ and the HDL-C level by $9.7 \%$, and the changes in adiponectin concentration were independently associated with those in the HDL-C level. ${ }^{136}$ Short-term exercise training has been shown to drastically increase adiponectin levels in overweight males. ${ }^{137}$ Because adiponectin is an important determinant of apoA-I catabolism, ${ }^{138}$ and adiponectin increases apoA-I synthesis and ABCA1 expression in the liver, ${ }^{16,139,140}$ the exercised-induced increase in adiponectin reduces the catabolism of HDL and increases the production of HDL leading to an increase in the HDL-C level.

Exercise training without weight loss (by controlling the diet and adjusting energy intake) has been shown to not only reduce the fractional catabolic rate of HDL but also to increase the synthetic rate of apoA-I in overweight men. ${ }^{118}$ Consistent with this finding, a recent study showed that exercise increased both the HDL-C level and the HDL particle number in overweight/ obese men. ${ }^{127}$ Exercise-induced protein content of AMP-activated protein kinase (AMPK) in skeletal muscle in these subjects was closely and positively correlated with the HDL-C and $\mathrm{HDL}_{2}-\mathrm{C}$ levels and HDL particle number. ${ }^{127}$ It is possible that exercise-induced changes in the liver contribute to the increased HDL-C level by increasing HDL neogenesis (Figure 7).

AMPK and nicotinamide adenine dinucleotide $\left(\mathrm{NAD}^{+}\right)$dependent protein deacetylases, sirtuins, are fuel-sensing enzymes that are present in all eukaryotic cells. ${ }^{141}$ Silent information regulator T1 (SIRT1) is the most studied of the 7 sirtuins that have been identified in mammalian cells. ${ }^{141}$ PPAR $\gamma$ coactivator $1 \alpha(\mathrm{PGC}-1 \alpha)$, which is activated via phosphorylation by AMPK ${ }^{142}$ and deacetylation by SIRT1 (Figure 7), ${ }^{143}$ coactivates multiple transcription factors, including nuclear receptor PPAR $\alpha,{ }^{144}$ to regulate the many genes involved in glucose and fatty acid metabolism. ${ }^{145}$ AMPK activates SIRT1 by increasing cellular $\mathrm{NAD}^{+}$levels, ${ }^{141,146}$ and SIRT1 in turn activates AMPK by deacetylation of the AMPK kinase serinethreonine liver kinase (LB1). ${ }^{141}$

Exercise increases the PPAR $\alpha$ protein content in skeletal muscle in humans, ${ }^{127}$ the AMPK activity in the liver, adipose tissue, and skeletal muscle in rats and mice, ${ }^{147-149}$ and the protein expression of SIRT1 and PGC- $1 \alpha$ in rat skeletal muscle..$^{150}$ AMPK, SIRT1, and PGC- $1 \alpha$ all positively regulate the transcriptional activity of PPAR $\alpha,{ }^{151,152}$ which is highly expressed in the liver, heart, and skeletal muscle. ${ }^{153}$ Activation of PPAR $\alpha$ increases the HDL-C level by increasing the production of apoA-I and apoA-II, and decreases the TG level by increasing the hepatic expression of LPL in humans. ${ }^{153}$

Furthermore, SIRT1 deacetylates and activates the nuclear receptor, LXR, which promotes transcription of the target genes involved in lipid metabolism, including the ABCA1 transporter. ${ }^{154}$ Deletion of SIRT1 reduced HDL-C production in mice and reduced ABCA1-mediated cholesterol efflux and HDL formation in cultured cells. ${ }^{154}$ Therefore, exercise-induced activation of enzymes (AMPK and SIRT1) and nuclear receptors (PPAR $\alpha$ and LXR) in the liver contributes to the production of HDL (Figure 7).

It is possible that the systemic effects of adiponectin and IL- 6 on the liver play a role in the exercise-induced increase in HDL neogenesis. Adiponectin has been shown to activate AMPK, SIRT1, and PCG- $1 \alpha$ in the skeletal muscle of mice via adiponectin receptor (AdipoR) $1 .{ }^{155}$ Adiponectin also promotes HDL production via increased apoA-I synthesis and ABCA1 expression in the liver. ${ }^{16,139,140}$ IL-6 is a cytokine (myokine) that is synthesized and released in large quantities from contracting skeletal muscle, which results in plasma concentrations that are 50- to 100-fold higher than those seen at rest. ${ }^{156}$ In rodents, IL-6 induced AMPK activity in muscle and adipose tissue. $^{149,157}$

\section{Conclusions}

HDL consists of heterogeneous particles that differ with respect to their lipid and protein composition, size, and electric charge. Although there has been a growing interest in HDL-directed therapies as well as statin therapy to resolve the residual risk factors for CAD, it is still unclear whether or not CETP inhibitors can reduce the risk of CAD. Low HDL-C levels are often complicated with metabolic disorders, and lifestyle changes, especially exercise, are effective for the prevention of cardiovascular disease. Therefore, although HDL-directed therapies that increase the HDL-C level and/or improve the function of $\mathrm{HDL}$ is a reasonable approach to reducing the residual risk of CAD as a complement to LDL-C-lowering therapy, lifestyle modifications including exercise to improve metabolic disorders should be considered as the first option.

\section{Acknowledgments}

This work was supported by grants-in-aid from the Ministry of Education, Culture, Sports, Science and Technology of Japan (Nos. 23590699, 24591123 , and 25461141), and by research grants from the Central Research Institute of Fukuoka University (2013-2015).

\section{Disclosures}

K.S.: Research and education grants, and promotional speaking fees (Y.U., S.M., K.S.) from MSD Co, Ltd, Pfizer Co, Ltd, and Eli Lilly and Company (Clinical Research grant), and K.S. and M.S. are Directors of ${ }^{\mathrm{NPO}}$ Clinical and Applied Science, Fukuoka, Japan. K.S. (Chairman) has an Endowed "Department of Molecular Cardiovascular Therapeutics" supported by MSD, Co, LTD. S.M. and Y.U. belong to the Department of Molecular Cardiovascular Therapeutics.

\section{References}

1. Zhang B, Miura S, Yanagi D, Noda K, Nishikawa H, Matsunaga A, et al. Reduction of charge-modified LDL by statin therapy in patients with CHD or CHD risk factors and elevated LDL-C levels: The SPECIAL Study. Atherosclerosis 2008; 201: 353-359.

2. Zhang B, Matsunaga A, Rainwater DL, Miura S, Noda K, Nishikawa $\mathrm{H}$, et al. Effects of rosuvastatin on electronegative LDL as characterized by capillary isotachophoresis: The ROSARY Study. J Lipid Res 2009; 50: $1832-1841$.

3. Saku K, Zhang B, Noda K. Randomized head-to-head comparison 
of pitavastatin, atorvastatin, and rosuvastatin for safety and efficacy (quantity and quality of LDL): The PATROL trial. Circ J 2011; 75: $1493-1505$

4. Zhang B, Kawachi E, Matsunaga A, Imaizumi S, Noda K, Uehara Y, et al. Reactivity of direct assays for low-density lipoprotein (LDL) cholesterol toward charge-modified LDL in hypercholesterolemia. Circ J 2012; 76: 2241-2248.

5. Mihaylova B, Emberson J, Blackwell L, Keech A, Simes J, Barnes $\mathrm{EH}$, et al. The effects of lowering LDL cholesterol with statin therapy in people at low risk of vascular disease: Meta-analysis of individual data from 27 randomised trials. Lancet 2012; 380: 581-590.

6. Kostis WJ, Cheng JQ, Dobrzynski JM, Cabrera J, Kostis JB. Metaanalysis of statin effects in women versus men. J Am Coll Cardiol 2012; 59: 572-582.

7. Cheng AY, Leiter LA. Implications of recent clinical trials for the National Cholesterol Education Program Adult Treatment Panel III guidelines. Curr Opin Cardiol 2006; 21: 400-404.

8. Grundy SM, Cleeman JI, Merz CN, Brewer HB Jr, Clark LT, Hunninghake DB, et al. Implications of recent clinical trials for the National Cholesterol Education Program Adult Treatment Panel III Guidelines. J Am Coll Cardiol 2004; 44: 720-732.

9. Barter P, Gotto AM, LaRosa JC, Maroni J, Szarek M, Grundy SM, et al. HDL cholesterol, very low levels of LDL cholesterol, and cardiovascular events. N Engl J Med 2007; 357: 1301-1310.

10. Manolio TA. Cohort studies and the genetics of complex disease. Nat Genet 2009; 41: 5-6.

11. Kontush A, Chapman MJ. High-density lipoproteins: Structure, metabolsim, function, and therapeutics. New Jersey: John Wiley \& Sons, 2012.

12. Voight BF, Peloso GM, Orho-Melander M, Frikke-Schmidt R, Barbalic M, Jensen MK, et al. Plasma HDL cholesterol and risk of myocardial infarction: A Mendelian randomisation study. Lancet 2012; 380: $572-580$.

13. Haase CL, Tybjaerg-Hansen A, Qayyum AA, Schou J, Nordestgaard BG, Frikke-Schmidt R. LCAT, HDL cholesterol and ischemic cardiovascular disease: A Mendelian randomization study of HDL cholesterol in 54, 500 individuals. J Clin Endocrinol Metab 2012; 97: E248-E256.

14. von Eckardstein A, Sibler RA. Possible contributions of lipoproteins and cholesterol to the pathogenesis of diabetes mellitus type 2. Curr Opin Lipidol 2011; 22: 26-32.

15. Ahmad T, Chasman DI, Buring JE, Lee IM, Ridker PM, Everett BM. Physical activity modifies the effect of LPL, LIPC, and CETP polymorphisms on HDL-C levels and the risk of myocardial infarction in women of European ancestry. Circ Cardiovasc Genet 2011; 4: 74-80.

16. Yamashita S, Tsubakio-Yamamoto K, Ohama T, Nakagawa-Toyama Y, Nishida M. Molecular mechanisms of HDL-cholesterol elevation by statins and its effects on HDL functions. $J$ Atheroscler Thromb 2010; 17: 436-451.

17. Cannon CP, Braunwald E, McCabe CH, Rader DJ, Rouleau JL, Belder R, et al. Intensive versus moderate lipid lowering with statins after acute coronary syndromes. N Engl J Med 2004; 350: $1495-$ 1504.

18. LaRosa JC, Grundy SM, Waters DD, Shear C, Barter P, Fruchart $\mathrm{JC}$, et al. Intensive lipid lowering with atorvastatin in patients with stable coronary disease. $N$ Engl J Med 2005; 352: 1425-1435.

19. Duffy D, Rader DJ. Emerging therapies targeting high-density lipoprotein metabolism and reverse cholesterol transport. Circulation 2006; 113: 1140-1150.

20. Cannon CP, Shah S, Dansky HM, Davidson M, Brinton EA, Gotto AM, et al. Safety of anacetrapib in patients with or at high risk for coronary heart disease. $N$ Engl J Med 2010; 363: 2406-2415.

21. Schwartz GG, Olsson AG, Abt M, Ballantyne CM, Barter PJ, Brumm J, et al. Effects of dalcetrapib in patients with a recent acute coronary syndrome. N Engl J Med 2012; 367: 2089-2099.

22. Perk J, De Backer G, Gohlke H, Graham I, Reiner Z, Verschuren WM, et al. European guidelines on cardiovascular disease prevention in clinical practice (version 2012): The Fifth Joint Task Force of the European Society of Cardiology and Other Societies on Cardiovascular Disease Prevention in Clinical Practice (constituted by representatives of nine societies and by invited experts). Atherosclerosis 2012; 223: 1-68.

23. Ton VK, Martin SS, Blumenthal RS, Blaha MJ. Comparing the new European cardiovascular disease prevention guideline with prior American Heart Association guidelines: An editorial review. Clin Cardiol 2013; 36: E1 -E6, doi:10.1002/clc.22079.

24. Kiens B, Lithell H. Lipoprotein metabolism influenced by traininginduced changes in human skeletal muscle. J Clin Invest 1989; 83: $558-564$.
25. Shiroma EJ, Lee IM. Physical activity and cardiovascular health: Lessons learned from epidemiological studies across age, gender, and race/ethnicity. Circulation 2010; 122: 743-752.

26. Goldstein JL, Brown MS. The LDL receptor. Arterioscler Thromb Vasc Biol 2009; 29: 431-438.

27. Rosenson RS, Brewer HB Jr, Davidson WS, Fayad ZA, Fuster V, Goldstein J, et al. Cholesterol efflux and atheroprotection: Advancing the concept of reverse cholesterol transport. Circulation 2012; 125: $1905-1919$

28. Murphy AJ, Bijl N, Yvan-Charvet L, Welch CB, Bhagwat N, Reheman A, et al. Cholesterol efflux in megakaryocyte progenitors suppresses platelet production and thrombocytosis. Nat Med 2013; 19: $586-594$

29. Schulman IG. Nuclear receptors as drug targets for metabolic disease. Adv Drug Deliv Rev 2010; 62: 1307-1315.

30. Zelcer N, Tontonoz P. Liver X receptors as integrators of metabolic and inflammatory signaling. J Clin Invest 2006; 116: 607-614.

31. Fielding CJ, Fielding PE. Molecular physiology of reverse cholesterol transport. J Lipid Res 1995; 36: 211-228.

32. Rye KA, Barter PJ. Predictive value of different HDL particles for the protection against or risk of coronary heart disease. Biochim Biophys Acta 2012; 1821: 473-480.

33. Rothblat GH, Phillips MC. High-density lipoprotein heterogeneity and function in reverse cholesterol transport. Curr Opin Lipidol 2010; 21: 229-238.

34. Rye KA, Bursill CA, Lambert G, Tabet F, Barter PJ. The metabolism and anti-atherogenic properties of HDL. J Lipid Res 2009; 50(Suppl): S195-S200.

35. Eisenberg S. High density lipoprotein metabolism. J Lipid Res 1984; 25: 1017-1058.

36. Tall AR. Plasma high density lipoproteins: Metabolism and relationship to atherogenesis. J Clin Invest 1990; 86: 379-384.

37. Lee JY, Lanningham-Foster L, Boudyguina EY, Smith TL, Young ER, Colvin PL, et al. Prebeta high density lipoprotein has two metabolic fates in human apolipoprotein A-I transgenic mice. $J$ Lipid Res 2004; 45: 716-728.

38. Timmins JM, Lee JY, Boudyguina E, Kluckman KD, Brunham LR, Mulya A, et al. Targeted inactivation of hepatic Abcal causes profound hypoalphalipoproteinemia and kidney hypercatabolism of apoA-I. J Clin Invest 2005; 115: 1333-1342.

39. Huuskonen J, Olkkonen VM, Jauhiainen M, Ehnholm C. The impact of phospholipid transfer protein (PLTP) on HDL metabolism. Atherosclerosis 2001; 155: 269-281.

40. McCoy MG, Sun GS, Marchadier D, Maugeais C, Glick JM, Rader DJ. Characterization of the lipolytic activity of endothelial lipase. $J$ Lipid Res 2002; 43: $921-929$.

41. Jaye M, Krawiec J. Endothelial lipase and HDL metabolism. Curr Opin Lipidol 2004; 15: 183-189.

42. Jahangiri A, Rader DJ, Marchadier D, Curtiss LK, Bonnet DJ, Rye KA. Evidence that endothelial lipase remodels high density lipoproteins without mediating the dissociation of apolipoprotein A-I. J Lipid Res 2005; 46: 896-903.

43 Webb NR, Cai L, Ziemba KS, Yu J, Kindy MS, van der Westhuyzen $\mathrm{DR}$, et al. The fate of HDL particles in vivo after SR-BI-mediated selective lipid uptake. J Lipid Res 2002; 43: 1890-1898.

44. de Beer MC, Webb NR, Whitaker NL, Wroblewski JM, Jahangiri A, van der Westhuyzen DR, et al. SR-BI selective lipid uptake: Subsequent metabolism of acute phase HDL. Arterioscler Thromb Vasc Biol 2009; 29: 1298-1303.

45. Harder CJ, McPherson R. HDL remodeling by CETP and SR-BI. In: Fielding CJ, editor. High-density lipoproteins: From basic biology to clinical aspects. WILEY-VCH Verlag GmbH \& Co. KGaA, Weinheim, Federal Republic of Germany, 2007; 163-182.

46. Gauthier A, Lau P, Zha X, Milne R, McPherson R. Cholesteryl ester transfer protein directly mediates selective uptake of high density lipoprotein cholesteryl esters by the liver. Arterioscler Thromb Vasc Biol 2005; 25: 2177-2184.

47. Cavelier C, Ohnsorg PM, Rohrer L, von Eckardstein A. The betachain of cell surface $\mathrm{F}(0) \mathrm{F}(1)$ ATPase modulates apoA-I and HDL transcytosis through aortic endothelial cells. Arterioscler Thromb Vasc Biol 2012; 32: 131-139.

48. Rohrer L, Ohnsorg PM, Lehner M, Landolt F, Rinninger F, von Eckardstein A. High-density lipoprotein transport through aortic endothelial cells involves scavenger receptor BI and ATP-binding cassette transporter G1. Circ Res 2009; 104: 1142-1150.

49. Cavelier C, Rohrer L, von Eckardstein A. ATP-Binding cassette transporter A1 modulates apolipoprotein A-I transcytosis through aortic endothelial cells. Circ Res 2006; 99: 1060-1066.

50. Tall AR. Cholesterol efflux pathways and other potential mechanisms involved in the athero-protective effect of high density lipo- 
proteins. J Intern Med 2008; 263: 256-273.

51. Hansson GK, Bjorkholm M. Medicine. Tackling two diseases with HDL. Science 2010; 328: 1641-1642.

52. Yvan-Charvet L, Wang N, Tall AR. Role of HDL, ABCA1, and ABCG1 transporters in cholesterol efflux and immune responses. Arterioscler Thromb Vasc Biol 2010; 30: 139-143.

53. Drew BG, Rye KA, Duffy SJ, Barter P, Kingwell BA. The emerging role of HDL in glucose metabolism. Nat Rev Endocrinol 2012; 8: $237-245$

54. Barter PJ, Nicholls S, Rye KA, Anantharamaiah GM, Navab M, Fogelman AM. Antiinflammatory properties of HDL. Circ Res 2004; 95: 764-772.

55. Saku K, Ahmad M, Glas-Greenwalt P, Kashyap ML. Activation of fibrinolysis by apolipoproteins of high density lipoproteins in man. Thromb Res 1985; 39: 1-8.

56. Khera AV, Cuchel M, de la Llera-Moya M, Rodrigues A, Burke MF, Jafri K, et al. Cholesterol efflux capacity, high-density lipoprotein function, and atherosclerosis. $N$ Engl J Med 2011; 364: $127-135$.

57. Patel PJ, Khera AV, Jafri K, Wilensky RL, Rader DJ. The antioxidative capacity of high-density lipoprotein is reduced in acute coronary syndrome but not in stable coronary artery disease. $J \mathrm{Am}$ Coll Cardiol 2011; 58: 2068-2075.

58. Yamamoto S, Yancey PG, Ikizler TA, Jerome WG, Kaseda R, Cox $\mathrm{B}$, et al. Dysfunctional high-density lipoprotein in patients on chronic hemodialysis. J Am Coll Cardiol 2012; 60: 2372-2379.

59. Ansell BJ, Navab M, Hama S, Kamranpour N, Fonarow G, Hough $\mathrm{G}$, et al. Inflammatory/antiinflammatory properties of high-density lipoprotein distinguish patients from control subjects better than high-density lipoprotein cholesterol levels and are favorably affected by simvastatin treatment. Circulation 2003; 108: 2751-2756.

60. Van Lenten BJ, Hama SY, de Beer FC, Stafforini DM, McIntyre TM, Prescott SM, et al. Anti-inflammatory HDL becomes pro-inflammatory during the acute phase response. Loss of protective effect of HDL against LDL oxidation in aortic wall cell cocultures. J Clin Invest 1995; 96: 2758-2767.

61. Heinecke J. HDL and cardiovascular-disease risk: Time for a new approach? N Engl J Med 2011; 364: 170-171.

62. Hoofnagle AN, Wu M, Gosmanova AK, Becker JO, Wijsman EM, Brunzell JD, et al. Low clusterin levels in high-density lipoprotein associate with insulin resistance, obesity, and dyslipoproteinemia. Arterioscler Thromb Vasc Biol 2010; 30: 2528-2534.

63. Wiesner P, Leidl K, Boettcher A, Schmitz G, Liebisch G. Lipid profiling of FPLC-separated lipoprotein fractions by electrospray ionization tandem mass spectrometry. J Lipid Res 2009; 50: $574-$ 585.

64. Rhee EP, Cheng S, Larson MG, Walford GA, Lewis GD, McCabe $\mathrm{E}$, et al. Lipid profiling identifies a triacylglycerol signature of insulin resistance and improves diabetes prediction in humans. J Clin Invest 2011; 121: 1402-1411.

65. Marsche G, Furtmuller PG, Obinger C, Sattler W, Malle E. Hypochlorite-modified high-density lipoprotein acts as a sink for myeloperoxidase in vitro. Cardiovasc Res 2008; 79: 187-194.

66. Zheng L, Nukuna B, Brennan ML, Sun M, Goormastic M, Settle $\mathrm{M}$, et al. Apolipoprotein A-I is a selective target for myeloperoxidase-catalyzed oxidation and functional impairment in subjects with cardiovascular disease. J Clin Invest 2004; 114: 529-541.

67. Hadfield KA, Pattison DI, Brown BE, Hou L, Rye KA, Davies MJ, et al. Myeloperoxidase-derived oxidants modify apolipoprotein A-I and generate dysfunctional HDL: Comparison of hypothiocyanous acid (HOSCN) with hypochlorous acid (HOCl). Biochem J 2013; 449: $531-542$.

68. Fisher EA, Feig JE, Hewing B, Hazen SL, Smith JD. High-density lipoprotein function, dysfunction, and reverse cholesterol transport. Arterioscler Thromb Vasc Biol 2012; 32: 2813-2820.

69. Navab M, Reddy ST, Van Lenten BJ, Fogelman AM. HDL and cardiovascular disease: Atherogenic and atheroprotective mechanisms. Nat Rev Cardiol 2011; 8: 222-232.

70. Iacob AO, Choudhury RP. Targeting HDL-cholesterol to reduce residual cardiovascular risk. Curr Opin Lipidol 2012; 23: 172-174.

71. Shah A, Rader DJ, Millar JS. The effect of PPAR-alpha agonism on apolipoprotein metabolism in humans. Atherosclerosis 2010; 210: $35-40$.

72. Barter PJ, Rye KA. Cardioprotective properties of fibrates: Which fibrate, which patients, what mechanism? Circulation 2006; 113: $1553-1555$.

73. Saku K, Gartside PS, Hynd BA, Kashyap ML. Mechanism of action of gemfibrozil on lipoprotein metabolism. J Clin Invest 1985; 75: $1702-1712$.

74. Staels B, Dallongeville J, Auwerx J, Schoonjans K, Leitersdorf E,
Fruchart JC. Mechanism of action of fibrates on lipid and lipoprotein metabolism. Circulation 1998; 98: 2088-2093.

75. Chapman MJ, Redfern JS, McGovern ME, Giral P. Niacin and fibrates in atherogenic dyslipidemia: Pharmacotherapy to reduce cardiovascular risk. Pharmacol Ther 2010; 126: 314-345.

76. Guyton JR, Bays HE. Safety considerations with niacin therapy. Am J Cardiol 2007; 99: 22C-31C.

77. Lavigne PM, Karas RH. The current state of niacin in cardiovascular disease prevention: A systematic review and meta-regression. $J$ Am Coll Cardiol 2013; 61: 440-446.

78. Kamanna VS, Kashyap ML. Mechanism of action of niacin. Am J Cardiol 2008; 101: 20B-26B.

79. Ikewaki K, Rader DJ, Sakamoto T, Nishiwaki M, Wakimoto N, Schaefer JR, et al. Delayed catabolism of high density lipoprotein apolipoproteins A-I and A-II in human cholesteryl ester transfer protein deficiency. J Clin Invest 1993; 92: 1650-1658.

80. Cuchel M, Rader DJ. Genetics of increased HDL cholesterol levels: Insights into the relationship between HDL metabolism and atherosclerosis. Arterioscler Thromb Vasc Biol 2003; 23: 1710-1712.

81. Nissen SE, Tardif JC, Nicholls SJ, Revkin JH, Shear CL, Duggan WT, et al. Effect of torcetrapib on the progression of coronary atherosclerosis. N Engl J Med 2007; 356: 1304-1316.

82. Kastelein JJ, van Leuven SI, Burgess L, Evans GW, Kuivenhoven $\mathrm{JA}$, Barter PJ, et al. Effect of torcetrapib on carotid atherosclerosis in familial hypercholesterolemia. N Engl J Med 2007; 356: 1620-1630.

83. Bots ML, Visseren FL, Evans GW, Riley WA, Revkin JH, Tegeler $\mathrm{CH}$, et al. Torcetrapib and carotid intima-media thickness in mixed dyslipidaemia (RADIANCE 2 study): A randomised, double-blind trial. Lancet 2007; 370: 153-160.

84. Barter PJ, Caulfield M, Eriksson M, Grundy SM, Kastelein JJ, Komajda M, et al. Effects of torcetrapib in patients at high risk for coronary events. $N$ Engl J Med 2007; 357: 2109-2122.

85. Fayad ZA, Mani V, Woodward M, Kallend D, Abt M, Burgess T, et al. Safety and efficacy of dalcetrapib on atherosclerotic disease using novel non-invasive multimodality imaging (dal-PLAQUE): A randomised clinical trial. Lancet 2011; 378: 1547-1559.

86. Luscher TF, Taddei S, Kaski JC, Jukema JW, Kallend D, Munzel $\mathrm{T}$, et al. Vascular effects and safety of dalcetrapib in patients with or at risk of coronary heart disease: The dal-VESSEL randomized clinical trial. Eur Heart J 2012; 33: 857-865.

87. Bloomfield D, Carlson GL, Sapre A, Tribble D, McKenney JM, Littlejohn TW 3rd, et al. Efficacy and safety of the cholesteryl ester transfer protein inhibitor anacetrapib as monotherapy and coadministered with atorvastatin in dyslipidemic patients. Am Heart J 2009; 157: $352-360$. e2.

88. Cao G, Beyer TP, Zhang Y, Schmidt RJ, Chen YQ, Cockerham SL, et al. Evacetrapib is a novel, potent, and selective inhibitor of cholesteryl ester transfer protein that elevates HDL cholesterol without inducing aldosterone or increasing blood pressure. J Lipid Res 2011; 52: $2169-2176$.

89. Nicholls SJ, Brewer HB, Kastelein JJ, Krueger KA, Wang MD, Shao M, et al. Effects of the CETP inhibitor evacetrapib administered as monotherapy or in combination with statins on HDL and LDL cholesterol: A randomized controlled trial. JAMA 2011; 306: 2099-2109.

90. Vergeer M, Bots ML, van Leuven SI, Basart DC, Sijbrands EJ, Evans GW, et al. Cholesteryl ester transfer protein inhibitor torcetrapib and off-target toxicity: A pooled analysis of the rating atherosclerotic disease change by imaging with a new CETP inhibitor (RADIANCE) trials. Circulation 2008; 118: 2515-2522.

91. Connelly MA, Parry TJ, Giardino EC, Huang Z, Cheung WM, $\mathrm{Chen} \mathrm{C}$, et al. Torcetrapib produces endothelial dysfunction independent of cholesteryl ester transfer protein inhibition. J Cardiovasc Pharmacol 2010; 55: 459-468.

92. Simic B, Hermann M, Shaw SG, Bigler L, Stalder U, Dorries C, et al. Torcetrapib impairs endothelial function in hypertension. Eur Heart J 2012; 33: 1615-1624.

93. Niesor EJ, Magg C, Ogawa N, Okamoto H, von der Mark E, Matile $\mathrm{H}$, et al. Modulating cholesteryl ester transfer protein activity maintains efficient pre-beta-HDL formation and increases reverse cholesterol transport. J Lipid Res 2010; 51: 3443-3454.

94. Shinkai H. Cholesteryl ester transfer-protein modulator and inhibitors and their potential for the treatment of cardiovascular diseases. Vasc Health Risk Manag 2012; 8: 323-331.

95. Schwartz GG, Olsson AG, Ballantyne CM, Barter PJ, Holme IM, Kallend D, et al. Rationale and design of the dal-OUTCOMES trial: Efficacy and safety of dalcetrapib in patients with recent acute coronary syndrome. Am Heart J 2009; 158: 896-901. e3.

96. REVEAL: Randomized EValuation of the Effects of Anacetrapib Through Lipid-modification. A Large-scale, Randomized Placebo- 
controlled Trial of the Clinical Effects of Anacetrapib Among People With Established Vascular Disease. http://clinicaltrials.gov/show/ NCT01252953 (accessed November 29, 2012).

97. A Study of Evacetrapib in High-Risk Vascular Disease (ACCELERATE). Assessment of Clinical Effects of Cholesteryl Ester Transfer Protein Inhibition With Evacetrapib in Patients at a High-Risk for Vascular Outcomes. http://clinicaltrials.gov/show/ NCT01687998 (accessed June 7, 2013).

98. Nissen SE, Tsunoda T, Tuzcu EM, Schoenhagen P, Cooper CJ, Yasin M, et al. Effect of recombinant ApoA-I Milano on coronary atherosclerosis in patients with acute coronary syndromes: A randomized controlled trial. JAMA 2003; 290: 2292-2300.

99. Angelin B, Parini P, Eriksson M. Reverse cholesterol transport in man: Promotion of fecal steroid excretion by infusion of reconstituted HDL. Atheroscler Suppl 2002; 3: 23-30.

100. Diditchenko S, Gille A, Pragst I, Stadler D, Waelchli M, Hamilton $\mathrm{R}$, et al. Novel Formulation of a Reconstituted High-Density Lipoprotein (CSL112) Dramatically Enhances ABCA1-Dependent Cholesterol Efflux. Arterioscler Thromb Vasc Biol 2013; 33: $2202-$ 2211.

101. Uehara Y, Ando S, Yahiro E, Oniki K, Ayaori M, Abe S, et al. FAMP, a novel apoA-I mimetic peptide, suppresses aortic plaque formation through promotion of biological HDL function in apoEdeficient mice. J Am Heart Assoc 2013; 2: e000048.

102. Imaizumi S, Navab M, Morgantini C, Charles-Schoeman C, Su F, Gao F, et al. Dysfunctional high-density lipoprotein and the potential of apolipoprotein A-1 mimetic peptides to normalize the composition and function of lipoproteins. Circ J 2011; 75: 1533-1538.

103. Singh IM, Shishehbor MH, Ansell BJ. High-density lipoprotein as a therapeutic target: A systematic review. JAMA 2007; 298: 786798.

104. Pownall HJ, Ballantyne CM, Kimball KT, Simpson SL, Yeshurun $\mathrm{D}$, Gotto AM Jr. Effect of moderate alcohol consumption on hypertriglyceridemia: A study in the fasting state. Arch Intern Med 1999; 159: $981-987$.

105. Asztalos B, Lefevre M, Wong L, Foster TA, Tulley R, Windhauser $M$, et al. Differential response to low-fat diet between low and normal HDL-cholesterol subjects. J Lipid Res 2000; 41: 321 -328.

106. Knopp RH, Walden CE, Retzlaff BM, McCann BS, Dowdy AA, Albers JJ, et al. Long-term cholesterol-lowering effects of 4 fat-restricted diets in hypercholesterolemic and combined hyperlipidemic men: The Dietary Alternatives Study. JAMA 1997; 278: 1509 1515.

107. Durstine JL, Grandjean PW, Davis PG, Ferguson MA, Alderson NL, DuBose KD. Blood lipid and lipoprotein adaptations to exercise: A quantitative analysis. Sports Med 2001; 31: 1033-1062.

108. Tseng ML, Ho CC, Chen SC, Huang YC, Lai CH, Liaw YP. A simple method for increasing levels of high-density lipoprotein cholesterol: a pilot study of combination aerobic- and resistanceexercise training. Int J Sport Nutr Exerc Metab 2013; 23: 271-281.

109. Hayashino Y, Jackson JL, Fukumori N, Nakamura F, Fukuhara S Effects of supervised exercise on lipid profiles and blood pressure control in people with type 2 diabetes mellitus: A meta-analysis of randomized controlled trials. Diabetes Res Clin Pract 2012; 98: $349-360$.

110. Kodama S, Tanaka S, Saito K, Shu M, Sone Y, Onitake F, et al. Effect of aerobic exercise training on serum levels of high-density lipoprotein cholesterol: A meta-analysis. Arch Intern Med 2007; 167: 999-1008.

111. Kelley GA, Kelley KS, Franklin B. Aerobic exercise and lipids and lipoproteins in patients with cardiovascular disease: A meta-analysis of randomized controlled trials. J Cardiopulm Rehabil 2006; 26: $131-134$.

112. Leon AS, Sanchez OA. Response of blood lipids to exercise training alone or combined with dietary intervention. Med Sci Sports Exerc 2001; 33: S502-S515, discussion S528-S509.

113. Thompson PD, Cullinane EM, Sady SP, Flynn MM, Bernier DN, Kantor MA, et al. Modest changes in high-density lipoprotein concentration and metabolism with prolonged exercise training. Circulation 1988; 78: 25-34

114. Crouse SF, O'Brien BC, Grandjean PW, Lowe RC, Rohack JJ, Green JS. Effects of training and a single session of exercise on lipids and apolipoproteins in hypercholesterolemic men. J Appl Physiol 1997; 83: 2019-2028.

115. Kraus WE, Houmard JA, Duscha BD, Knetzger KJ, Wharton MB, McCartney JS, et al. Effects of the amount and intensity of exercise on plasma lipoproteins. N Engl J Med 2002; 347: 1483-1492.

116. Durstine JL, Grandjean PW, Cox CA, Thompson PD. Lipids, lipoproteins, and exercise. J Cardiopulm Rehabil 2002; 22: 385-398.

117. Kelley GA, Kelley KS. Aerobic exercise and HDL2-C: A meta- analysis of randomized controlled trials. Atherosclerosis 2006; 184: 207-215.

118. Thompson PD, Yurgalevitch SM, Flynn MM, Zmuda JM, SpannausMartin D, Saritelli A, et al. Effect of prolonged exercise training without weight loss on high-density lipoprotein metabolism in overweight men. Metabolism 1997; 46: 217-223.

119. Casella-Filho A, Chagas AC, Maranhao RC, Trombetta IC, Cesena $\mathrm{FH}$, Silva VM, et al. Effect of exercise training on plasma levels and functional properties of high-density lipoprotein cholesterol in the metabolic syndrome. Am J Cardiol 2011; 107: 1168-1172.

120. Szostak J, Laurant $P$. The forgotten face of regular physical exercise: A 'natural' anti-atherogenic activity. Clin Sci (Lond) 2011; 121: 91-106.

121. Joyner MJ, Green DJ. Exercise protects the cardiovascular system: Effects beyond traditional risk factors. J Physiol 2009; 587: 55515558 .

122. Gleeson M, Bishop NC, Stensel DJ, Lindley MR, Mastana SS, Nimmo MA. The anti-inflammatory effects of exercise: Mechanisms and implications for the prevention and treatment of disease. Nat Rev Immunol 2011; 11: 607-615.

123. Pedersen BK, Febbraio MA. Muscles, exercise and obesity: Skeletal muscle as a secretory organ. Nat Rev Endocrinol 2012; 8: 457-465.

124. Brandt C, Pedersen BK. The role of exercise-induced myokines in muscle homeostasis and the defense against chronic diseases. $J$ Biomed Biotechnol 2010; 2010: 520258.

125. Pedersen BK, Febbraio MA. Muscle as an endocrine organ: Focus on muscle-derived interleukin-6. Physiol Rev 2008; 88: 1379-1406.

126. Nielsen S, Pedersen BK. Skeletal muscle as an immunogenic organ. Curr Opin Pharmacol 2008; 8: 346-351.

127. Greene NP, Fluckey JD, Lambert BS, Greene ES, Riechman SE, Crouse SF. Regulators of blood lipids and lipoproteins? PPARdelta and AMPK, induced by exercise, are correlated with lipids and lipoproteins in overweight/obese men and women. Am J Physiol Endocrinol Metab 2012; 303: E1212-E1221.

128. Couillard C, Despres JP, Lamarche B, Bergeron J, Gagnon J, Leon $\mathrm{AS}$, et al. Effects of endurance exercise training on plasma HDL cholesterol levels depend on levels of triglycerides: Evidence from men of the Health, Risk Factors, Exercise Training and Genetics (HERITAGE) Family Study. Arterioscler Thromb Vasc Biol 2001; 21: $1226-1232$.

129. Movva R, Rader DJ. Laboratory assessment of HDL heterogeneity and function. Clin Chem 2008; 54: 788-800.

130. Camont L, Chapman MJ, Kontush A. Biological activities of HDL subpopulations and their relevance to cardiovascular disease. Trends Mol Med 2011; 17: 594-603.

131. Irving BA, Davis CK, Brock DW, Weltman JY, Swift D, Barrett EJ, et al. Effect of exercise training intensity on abdominal visceral fat and body composition. Med Sci Sports Exerc 2008; 40: $1863-$ 1872.

132. Katzmarzyk PT, Leon AS, Rankinen T, Gagnon J, Skinner JS, Wilmore JH, et al. Changes in blood lipids consequent to aerobic exercise training related to changes in body fatness and aerobic fitness. Metabolism 2001; 50: $841-848$.

133. Gleeson M, Bishop NC, Stensel DJ, Lindley MR, Mastana SS, Nimmo MA. The anti-inflammatory effects of exercise: Mechanisms and implications for the prevention and treatment of disease. Nat Rev Immunol 2011; 11: 607-615.

134. Ouchi N, Parker JL, Lugus JJ, Walsh K. Adipokines in inflammation and metabolic disease. Nat Rev Immunol 2011; 11: 85-97.

135. Ryo M, Nakamura T, Kihara S, Kumada M, Shibazaki S, Takahashi $\mathrm{M}$, et al. Adiponectin as a biomarker of the metabolic syndrome. Circ J 2004; 68: 975-981.

136. Belalcazar LM, Lang W, Haffner SM, Hoogeveen RC, Pi-Sunyer FX, Schwenke DC, et al. Adiponectin and the mediation of HDLcholesterol change with improved lifestyle: The Look AHEAD Study. J Lipid Res 2012; 53: 2726-2733.

137. Kriketos AD, Gan SK, Poynten AM, Furler SM, Chisholm DJ, Campbell LV. Exercise increases adiponectin levels and insulin sensitivity in humans. Diabetes Care 2004; 27: 629-630.

138. Verges B, Petit JM, Duvillard L, Dautin G, Florentin E, Galland F, et al. Adiponectin is an important determinant of apoA-I catabolism. Arterioscler Thromb Vasc Biol 2006; 26: 1364-1369.

139. Matsuura F, Oku H, Koseki M, Sandoval JC, Yuasa-Kawase M, Tsubakio-Yamamoto K, et al. Adiponectin accelerates reverse cholesterol transport by increasing high density lipoprotein assembly in the liver. Biochem Biophys Res Commun 2007; 358: 1091-1095.

140. Oku H, Matsuura F, Koseki M, Sandoval JC, Yuasa-Kawase M, Tsubakio-Yamamoto K, et al. Adiponectin deficiency suppresses ABCA1 expression and ApoA-I synthesis in the liver. FEBS Lett 2007; 581: 5029-5033. 
141. Ruderman NB, Xu XJ, Nelson L, Cacicedo JM, Saha AK, Lan F, et al. AMPK and SIRT1: A long-standing partnership? Am J Physiol Endocrinol Metab 2010; 298: E751-E760.

142. Jager S, Handschin C, St-Pierre J, Spiegelman BM. AMP-activated protein kinase (AMPK) action in skeletal muscle via direct phosphorylation of PGC-1alpha. Proc Natl Acad Sci USA 2007; 104: 12017-12022.

143. Haigis MC, Guarente LP. Mammalian sirtuins: Emerging roles in physiology, aging, and calorie restriction. Genes Dev 2006; 20: 2913-2921.

144. Canto C, Auwerx J. PGC-1alpha, SIRT1 and AMPK, an energy sensing network that controls energy expenditure. Curr Opin Lipidol 2009; 20: 98-105.

145. Dominy JE Jr, Lee Y, Gerhart-Hines Z, Puigserver P. Nutrientdependent regulation of PGC-1alpha's acetylation state and metabolic function through the enzymatic activities of Sirt1/GCN5. Biochim Biophys Acta 2010; 1804: 1676-1683.

146. Canto C, Gerhart-Hines Z, Feige JN, Lagouge M, Noriega L, Milne $\mathrm{JC}$, et al. AMPK regulates energy expenditure by modulating NAD+ metabolism and SIRT1 activity. Nature 2009; 458: 1056-1060.

147. Kelly M, Keller C, Avilucea PR, Keller P, Luo Z, Xiang X, et al. AMPK activity is diminished in tissues of IL-6 knockout mice: The effect of exercise. Biochem Biophys Res Commun 2004; 320: 449 454.

148. Richter EA, Ruderman NB. AMPK and the biochemistry of exercise: Implications for human health and disease. Biochem J 2009; 418: $261-275$.

149. Ruderman NB, Keller C, Richard AM, Saha AK, Luo Z, Xiang X, et al. Interleukin-6 regulation of AMP-activated protein kinase: Potential role in the systemic response to exercise and prevention of the metabolic syndrome. Diabetes 2006; 55(Suppl 2): S48-S54.

150. Suwa M, Nakano H, Radak Z, Kumagai S. Endurance exercise increases the SIRT1 and peroxisome proliferator-activated receptor gamma coactivator-1alpha protein expressions in rat skeletal muscle. Metabolism 2008; 57: 986-998.

151. Fulco M, Sartorelli V. Comparing and contrasting the roles of AMPK and SIRT1 in metabolic tissues. Cell Cycle 2008; 7: 3669-3679.

152. Lomb DJ, Laurent G, Haigis MC. Sirtuins regulate key aspects of lipid metabolism. Biochim Biophys Acta 2010; 1804: 1652-1657.

153. Burri L, Thoresen GH, Berge RK. The role of PPARalpha activation in liver and muscle. PPAR Res 2010; 2010: Article ID 542359,11 pages.

154. Li X, Zhang S, Blander G, Tse JG, Krieger M, Guarente L. SIRT1 deacetylates and positively regulates the nuclear receptor LXR. Mol Cell 2007; 28: $91-106$

155. Iwabu M, Yamauchi T, Okada-Iwabu M, Sato K, Nakagawa T, Funata M, et al. Adiponectin and AdipoR1 regulate PGC-1alpha and mitochondria by $\mathrm{Ca}^{2+}$ and AMPK/SIRT1. Nature 2010; 464: $1313-1319$.

156. Febbraio MA, Pedersen BK. Muscle-derived interleukin-6: Mechanisms for activation and possible biological roles. FASEB J 2002; 16: $1335-1347$.

157. Kelly M, Gauthier MS, Saha AK, Ruderman NB. Activation of AMPactivated protein kinase by interleukin-6 in rat skeletal muscle: Association with changes in cAMP, energy state, and endogenous fuel mobilization. Diabetes 2009; 58: 1953-1960. 